Louisiana State University

LSU Digital Commons

2005

\title{
The influence of transdermally administered fentanyl on isoflurane requirements in normothermic and hypothermic dogs
}

Diane Wilson

Louisiana State University and Agricultural and Mechanical College

Follow this and additional works at: https://digitalcommons.Isu.edu/gradschool_theses

Part of the Veterinary Medicine Commons

\section{Recommended Citation}

Wilson, Diane, "The influence of transdermally administered fentanyl on isoflurane requirements in normothermic and hypothermic dogs" (2005). LSU Master's Theses. 3610.

https://digitalcommons.Isu.edu/gradschool_theses/3610

This Thesis is brought to you for free and open access by the Graduate School at LSU Digital Commons. It has been accepted for inclusion in LSU Master's Theses by an authorized graduate school editor of LSU Digital Commons. For more information, please contact gradetd@lsu.edu. 
THE INFLUENCE OF TRANSDERMALLY ADMINISTERED

FENTANYL ON ISOFLURANE REQUIREMENTS

IN NORMOTHERMIC AND HYPOTHERMIC DOGS

\author{
A Thesis \\ Submitted to the Graduate Faculty of the \\ Louisiana State University and \\ Agricultural and Mechanical College \\ in partial fulfillment of the \\ requirements for the degree of \\ Master of Science
}

In

The Interdepartmental Program in

Veterinary Medical Sciences through the

Department of Veterinary Clinical Sciences

by

Diane Wilson

D.V.M., Louisiana State University, 2001

May 2005 


\section{DEDICATION}

To my husband, mother and father,

Also to Bruno, Kookie, Grubs, Spit, Shine and all the other faithful canine companions in my life. 


\section{ACKNOWLEDGEMENTS}

I would like to acknowledge the members of my masters committee, Dr. Glenn Pettifer, Dr. Giselle Hosgood, and Dr. Claudio Natalini. I am grateful to Dr. Natalini for his assistance with the technical aspects of the research, especially the Grass 88 electrical stimulator. I owe a debt of gratitude to Dr. Hosgood for all her support and advice needed to complete the analysis of the data and also for her encouragement. Dr. Pettifer has provided me with mentorship, friendship, and unwavering support during my residency and masters program. I consider myself privileged to have worked with each of them.

I would like to thank Dr. Anderson da Cunha and Dr. Luis Lopez for their friendship, support and good humor.

My thanks are also due to the very knowledgeable, helpful and supportive technicians with whom I have worked over the past three years, Mr. Harvey Westbrook, Mr. Scott Boatwright, Ms. Nicole Fitzgerald, and Ms. Rouchelle Gage.

Thank you to the Louisiana State University School of Veterinary Medicine VCS CORP Fund for financial support. 


\section{TABLE OF CONTENTS}

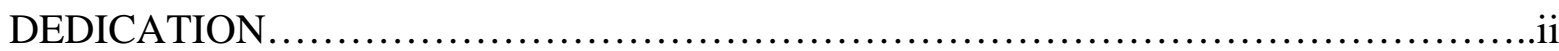

ACKNOWLEDGEMENTS .........................................................

LIST OF TABLES........................................................................

LIST OF FIGURES................................................................

ABSTRACT ..................................................................... viii

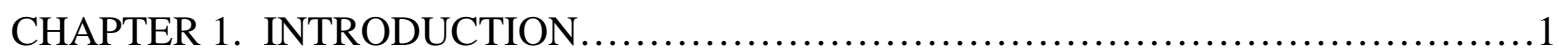

1.1 Use of Fentanyl in Animals..................................................

1.2 Use of Fentanyl in People..................................................

1.3 Respiratory Depression in Dogs...........................................

1.4 Post-operative Analgesia.................................................

1.5 Inhalant Anesthetic Reductions.............................................

CHAPTER 2. REVIEW OF LITERATURE..........................................6

2.1 Pain (nociception)........................................................

2.2 Physiological Processes Involved in Nociceptive Pathways......................8

2.2.1 Transduction..........................................................

2.2.2 Transmission....................................................... 9

2.2.3 Endogenous Modulation of Nociceptive Transmission.................9

2.2.4 Perception.....................................................

2.3 Peripheral Sensitization................................................... 12

2.4 Central Sensitization......................................................

2.5 Hyperalgesia................................................................

2.6 Multimodal Approach to Analgesia.............................................14

2.6.1 Local Anesthetics..................................................14

2.6.2 Non Steroidal Anti-inflammatory Drugs (NSAIDs)....................14

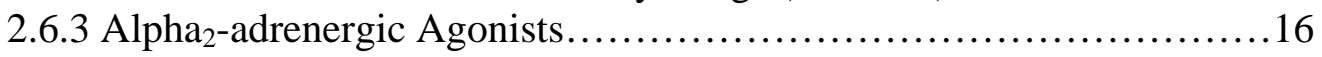

2.6.4 N-methyl-D-aspartate antagonists...............................16

2.6 .5 Opioids............................................................ 16

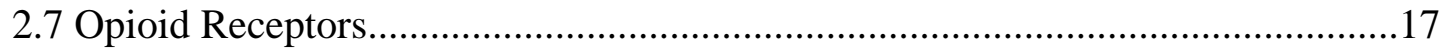

2.7.1 Classification and Distribution of Opioid Receptors..................17

2.7.2 Cellular Mechanisms..............................................18

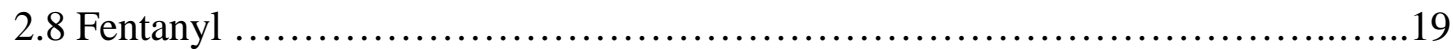

2.8.1 Routes of administration..........................................

2.8.2 Pharmacokinetics................................................... 19

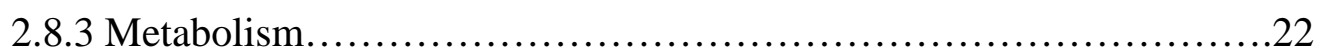

2.8.4 Pharmacodynamics.............................................22

2.8.5 Antagonism....................................................23

2.9 Transdermal Fentanyl....................................................23

2.9.1 Components of a Transdermal Fentanyl Patch....................................24

2.9.2 Application of a Transdermal Fentanyl Patch.........................24

2.9.3 Plateau Serum Fentanyl Levels Following Application... ..............25

2.9.4 Side Effects...................................................25

2.9.5 Therapeutic uses in Veterinary Medicine............................27 
2.10 Evaluation of Analgesia during General Anesthesia ..........................27

2.11 Minimum Alveolar Concentration...........................................28

2.11.1 Determination of Minimum Alveolar Concentration......................28

2.11.2 Supramaximal Stimulation.....................................29

2.11.3 Determination of Minimum Alveolar Concentration in Dogs..........29

2.12 Thermoregulation .........................................................

2.13 Effect of General Anesthesia on Thermoregulation ...........................31

2.13.1 Influence of Temperature on Minimum Alveolar Concentration.......33

2.14 Autoregulation of Blood Flow .............................................34

2.15 Effects of Hypothermia on Tissue Blood Flow...................................34

2.16 Effects of Isoflurane on Tissue Blood Flow..................................35

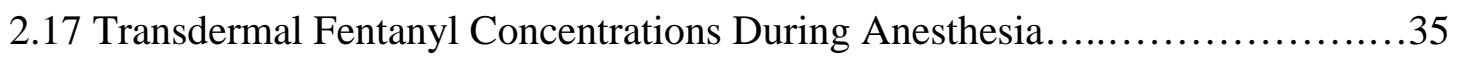

2.18 Hypothesis and Objectives for Study......................................36

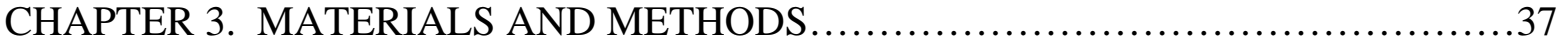

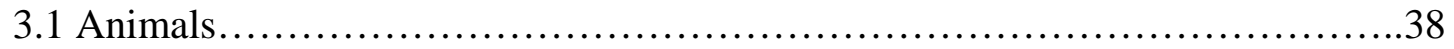

3.2 Anesthesia and Instrumentation........................................... 39

3.3 Data Collection............................................................ 40

3.4 Body Temperature.....................................................40

3.5 Determination of Minimum Alveolar Concentration............................41

3.6 Fentanyl Concentration Determination....................................42

3.7 Statistical Analysis.................................................44

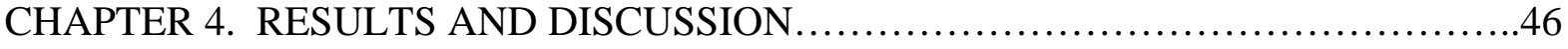

4.1 Results............................................................... 47

4.2 Discussion.............................................................. 48

REFERENCES................................................................. 52

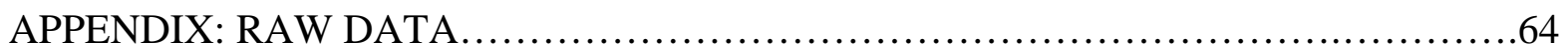

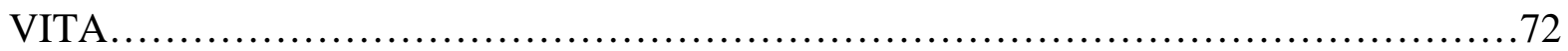




\section{LIST OF TABLES}

Table 1. Effects of short- and long-term administration of opioids.......................20

Table 2. Factors that affect minimum alveolar concentration...........................31 


\section{LIST OF FIGURES}

Figure 1. The Arachadonic acid cascade..........................................15

Figure 2. The chemical structure of fentanyl......................................

Figure 3. Transdermal fentanyl patch............................................ 24

Figure 4. Decrease in temperature during general anesthesia...........................32

Figure 5. The relationship between blood flow, pressure, and resistance to flow can be expressed as a variant of Ohm's law...................................................

Figure 6. Mean ( \pm SEM) Minimum Alveolar Concentration (\%) for isoflurane C-NORM (control normothermia), C-HYPO (control hypothermia), F-NORM (fentanyl

normothermia), and F-HYPO (fentanyl hypothermia)..... .47 


\begin{abstract}
Intraoperative reductions in serum fentanyl levels in dogs with induced moderate hypothermia and transdermal fentanyl patches (TDF) in place has been documented. The impact of such reductions has not been evaluated nor has the anesthetic sparing effect of the TDF. Reductions in serum levels may be the result of either a decreased uptake of fentanyl from the dermal depot, or a biophase shift. The objective of this investigation was to determine whether the minimum alveolar concentration (MAC) of isoflurane was altered in the presence of TDF in normothermic and hypothermic dogs.
\end{abstract}

Six mature, healthy, mixed breed dogs were anesthetized on four separate occasions, and received each of the 4 following treatments in random order: 1 . Sham patchnormothermia (C-NORM), 2. Sham patch-hypothermia (C-HYPO), 3. Fentanyl patchnormothermia (F-NORM), 4. Fentanyl hypothermia (F-HYPO). The appropriate patch was applied twenty four hours prior to induction of anesthesia. Anesthesia was induced with isoflurane in oxygen; the dogs were intubated and mechanical ventilation was initiated. Target temperatures $\left(34.5^{\circ} \mathrm{C}\right.$ - HYPO, or within $1^{\circ} \mathrm{C}$ of baseline- NORM) were held constant for one hour prior to beginning the MAC determinations. Supramaximal stimulation was produced by an electrical stimulator which delivered a current to needle electrodes in the buccal mucosa of the lower jaw of the dog. The MAC ( \pm SD) for C-NORM, C-HYPO, FNORM and F-HYPO was $1.2 \pm 0.17,0.855 \pm 0.183,0.763 \pm 0.097$, and $0.830 \pm 0.172$ respectively. MAC for C-NORM was significantly higher than the other groups. There was no significant difference between C-HYPO, F-NORM, and F-HYPO.

Transdermal fentanyl reduces the isoflurane requirement in normothermic dogs. The presence of hypothermia appears to negate the effects of TDF. 
CHAPTER 1. INTRODUCTION 


\subsection{Use of Fentanyl in Animals}

Most animals requiring general anesthesia are subjected to a surgical or medical procedure. Many of these procedures are associated with tissue trauma that leads to the experience of pain. In these instances, administration of analgesic drugs, such as opioids, as part of a multi-modal approach to pain management is often warranted. Fentanyl is a mu $\left(\mathrm{OP}_{3}\right)$ opioid agonist, available in injectable, transmucosal, and transdermal preparations that is frequently used for the control of pain in animals and people. Transdermal fentanyl (TDF) has been used in pain management protocols in people, dogs, cats, horses, rabbits, sheep, goats and pigs (Broome et al. 1995; Kyles et al. 1998; Glerum et al. 2001; Matthews et al. 1997; Foley et al. 2001; Dowd et al. 1997; Carroll et al.1999; and Harvey-Clark et al. 2000).

\subsection{Use of Fentanyl in People}

Transdermal administration of fentanyl is contraindicated in people for management of acute or post-operative pain because of the potential for profound respiratory depression (Grond et al. 2000). In addition, the non-titratable nature of transdermal drug delivery systems may make them unsuitable for the delivery of immediate post operative analgesia. Instead, postoperative analgesic needs are often managed using a patient controlled administration device while the TDF delivery system is used primarily for the management of chronic pain in people with cancer.

The use of a patient controlled system is not feasible in animals, therefore other types of delivery system must be considered. Transdermal delivery systems for fentanyl provide a convenient form of dosing a mu opioid agent. Such a system provides longer term pain management of up to 72 hours for animals in the 24-36 hours following surgery compared with bolus injections or oral medications; the need for additional equipment or invasive catheters is also negated. 


\subsection{Respiratory Depression in Dogs}

Respiratory depression via direct depression of the brain stem respiratory centers is associated with the administration of mu opioid agonists in people. Hypoventilation after surgery is not observed in dogs that have received high doses (average dose of $4.8 \mu \mathrm{g} / \mathrm{kg} / \mathrm{hr}$ ) of fentanyl transdermally beginning 24 hours prior to surgery and continued for 48 hours following surgery (Welch et al, 2002). The lack of associated respiratory depression in dogs may make TDF a suitable choice for analgesia during surgery and for the first 48 hours following surgery.

\subsection{Post-operative Analgesia}

Transdermal fentanyl is used frequently for pain management in the 48 hours following surgery. Transdermal fentanyl provides equal or better analgesia than epidural morphine in dogs undergoing orthopedic surgery (Robinson et al. 1999). Cats undergoing onychectomy demonstrate better recovery scores (e.g. less vocalizing), lower levels of sedation, and lower pain scores after receiving fentanyl transdermally compared to cats receiving butorphanol intravenously (Franks et al. 2000). The transdermal system offers ease of administration, decreased frequency of dosing, no need for venous access or frequent intramuscular injections, and also the ability to provide analgesia to animals on an outpatient basis.

\subsection{Inhalant Anesthetic Reductions}

The TDF patch is often applied 24 hours before surgery. This allows time (approximately 24 hours) for the drug to reach serum concentrations that provide analgesia, prior to the surgical trauma, although variations occur between species and individual animals. In addition, the presence of a mu opioid agonist during surgery should reduce the inhalant anesthetic requirements (Steffey et al. 1994). This reduction in inhalant 
concentration may be associated with significant reductions in the negative cardiovascular effects of the inhalant (Muir et al. 2003).

In normothermic cats receiving fentanyl transdermally, the requirement for isoflurane is significantly reduced (Yackey et al, 2004). Interestingly, cats anesthetized with isoflurane in the presence of moderate hypothermia show significant reductions in serum fentanyl levels during the anesthesia period(Pettifer and Hosgood, 2003). Dogs with moderate hypothermia also show significant reductions in serum fentanyl concentrations during anesthesia (Pettifer and Hosgood, 2004). The effect of these reductions in serum fentanyl concentrations on inhaled anesthetic requirements in dogs and cats with moderate hypothermia during anesthesia is not known.

Reductions in serum fentanyl concentrations during anesthesia associated with hypothermia may be the result of decreased uptake of fentanyl from the dermal depots. Changes in peripheral perfusion could alter the uptake of fentanyl and result in decreased effectiveness of a TDF patch during the anesthesia period. In contrast, volatile anesthetics also play a role in alterations in peripheral circulation which vary with the individual inhalants. Isoflurane administration causes mild peripheral vasodilation which could increase the uptake of fentanyl administered via the transdermal route.

The decrease in serum fentanyl concentrations in hypothermic dogs may not be due to a decrease in uptake at all. It is possible that the decreased serum fentanyl concentration was a result of the fentanyl moving from the serum to the site of action (or biophase) in the interstitial fluid. If this occurred, an increase in pharmacologic effect manifested by lower inhalant concentrations despite the reduced serum fentanyl concentrations might be expected. 
This investigation is an assessment of the impact of the transdermal administration of fentanyl on inhaled anesthetic requirements in normothermic and hypothermic isoflurane anesthetized dogs. 
CHAPTER 2. REVIEW OF LITERATURE 


\subsection{Pain (nociception)}

Pain or nociception has been defined by the International Association for the Study of Pain as "an unpleasant sensory and emotional experience associated with actual or potential tissue damage" (Merskey, 1979).

The experience of pain may be exhibited in various ways and involves complex and dynamic biological sequences which change with the type and duration of associated stimulation. Pain has been classified in a number of ways that describe the sensation but imprecisely document pain. Somatic pain describes that which is well localized, sharp and definite, often constant and occurring at the site of the stimulus. In contrast, visceral pain may be poorly localized, vague or dull, and periodic in nature. Inflammatory pain describes pain associated with the release of inflammatory mediators in response injury. Physiologic pain serves as a protective mechanism to prevent the body from potential injury. Pathologic pain describes pain in an area of sensory loss, or in the absence of ongoing tissue damage in conjunction with allodynia (the experience of pain associated with non painful stimuli) and hyperalgesia (an increased response to stimulus). Pain may also be described as fast pain or slow pain depending on the nerve fibers involved in transmitting the signals to the central nervous system.

Fast pain is the result of stimulation of small, myelinated A-delta nerve fibers with a conduction velocity of $6-30 \mathrm{~m} / \mathrm{s}$. Stimulation of fast pain fibers is associated with mechanical (mechanosensitive) and/or thermal (mechanothermal) stimuli such as a pin prick or a surgical incision.

Slow pain is associated with stimulation of unmyelinated type $\mathrm{C}$ nerve fibers with a conduction velocity of $0.5-2 \mathrm{~m} / \mathrm{s}$. Stimulation of slow pain fibers is associated with mechanical, thermal or chemical (polymodal) stimulation and causes throbbing or aching types of pain. 
Chemicals capable of activating nociceptors include bradykinin, serotonin, histamine, acetylcholine, and potassium ions. Substance P (an 11-amino acid peptide) does not directly excite nociceptors, but when released from nerve endings it results in vasodilation and an increase in vascular permeability (Dahl and Kehlet, 1991). Prostaglandins are also involved indirectly in that they sensitize nociceptors but are unable to excite them directly.

\subsection{Physiolgical Processes Involved in Nociceptive Pathways}

The four major physiologic processes involved in the nociceptive pathway are:

1. Transduction of the noxious stimuli into electrical activity at the sensory nerve endings.

2. Transmission of the impulses throughout the sensory nervous system.

3. Endogenous modulation or modification of nociceptive transmission.

4. Perception of pain.

\subsubsection{Transduction}

Nociceptive receptors must be present in order to detect stimuli to initiate the pain pathway. Nociceptors (peripheral receptors) are naked afferent nerve endings of myelinated A-Delta or unmyelinated $\mathrm{C}$ fibers that encode occurrence, intensity, duration, and location of noxious stimuli. The stimuli can be mechanical, thermal, or chemical in nature. The type of pain perceived will depend in part on the nerve fibers involved in the conduction of the impulse. Four classes of nociceptors have been identified: mechanical, thermal, polymodal, and silent.

Nociceptive neurons that are activated by noxious stimuli change or transduce these stimuli into electrical signals and generate action potentials in afferent A-delta and C nerve fibers. Transduction is mediated by membrane bound receptors that are activated according to the type of stimulation. Noxious mechanical stimuli are mediated by acid sensing ion channels (ASIC) (Page et al. 2004) thermal stimuli by vanilloid receptor-1 (VR1) (Nagy et 
al. 2004), and chemical stimuli by purinergic receptor subtype-3 (P2X3) (Wu et al. 2004). Sensory impulse generation begins when a stimulus causes an increase in the permeability of the membrane of sensory endings to various ions. Ions flow through channels following their electrical and concentration gradients producing partial depolarization of sensory endings (generator potential). In addition to the slow generator depolarization, there is a triggering of more sensitive sodium channels which augments depolarization and is often referred to as a spike or nerve impulse.

\subsubsection{Transmission}

Electrical impulses that are generated from the transduction of the input to the nociceptors are transmitted to the spinal cord by A-Delta or C fibers which have cell bodies located in the dorsal root ganglia. Neurons in nociceptive pathways synapse with local interneurons or projection neurons in the dorsal horn of the spinal cord. In the dorsal horn of the spinal cord, the release of excitatory neurotransmitters such as glutamate, neurokinins (substance P), tachykinins, and calcitonin gene-related peptide, are required for further transmission of pain to higher centers in the thalamus, brainstem, and cerebral cortex via multiple spinal cord pathways (Hudspith, 1997; Yaksh and Hammond, 1982).

The spinal cord pathways are divided into two groups based on location. The lateral group includes the neospinothalamic tract, the spinocervical tract, and the dorsal columnpostsynaptic tract. The medial group includes the paleospinothalamic tract, the spinoreticular tract, the spinomesencephalic tract, and the propriospinal tract. There are major interspecies differences in these systems, for example the spinocervical tract is well developed in cats but not in primates (Dennis and Melzack, 1977).

\subsubsection{Endogenous Modulation of Nociceptive Transmission}

Transmission of impulses is modulated by the activation of descending inhibitory pathways that extend between the brain and spinal cord. A descending pathway has four 
components; A. Cortical and diencephalic, B. Mesencephalic periaqueductal gray matter and periventricular gray matter, C. Rostroventral medulla and pons of midbrain, and D. Medullary and spinal cord dorsal horn (Cousins and Mather,1984).

\subsubsection{Cortical and Diencephalic}

Structures such as the spinal cord which project fibers to the brain also receive descending fibers from the cortex. This cortical input influences cephalad transmission at the level of the thalamus, reticular formation, trigeminal system, and spinal cord. These structures in turn influence cephalad transmission of impulses to lower synapses including reticulospinal and rubrospinal which project to several laminae of the spinal cord (Cousins and Mather, 1984).

\subsubsection{Mesencephalic Periaqueductal Grey Matter (PAG) and Periventricular Gray Matter (PVG)}

The mesencephalic PAG and PVG are substantial contributors to the endogenous analgesic system (Carsten et al. 1979). Antinociceptive effects are thought to be mediated largely by endogenous opioid activation of the PAG outflow, probably operating through a gama-aminobutyric acid (GABA) containing interneuron. In addition the PAG has direct descending projections to the dorsal horn and ascending projections to the intralaminar nuclei of the thalamus (Lamont et al. 2000).

\subsubsection{Rostroventral Medulla and Pons of the Midbrain}

A large population of brain stem cells in the ventral rostral medulla and caudal pons project to the dorsal horn. These cells are concentrated in the nucleus raphe magnus, and the nucleus reticularis magnocellularis. These nuclei receive input from the PAG, send fibers to the spinal cord, and produce antinociception (inhibition of the perception and/or transmission of pain) when stimulated (Coggeshall et al. 1981; Willis, 1985; Yaksh and Hammond, 1982; Mantyh, 1983). 


\subsubsection{Medullary and Spinal Cord Dorsal Horn}

Communication between dorsal horn neurons is complex. The role of the dorsal horn in antinociception was first acknowledged by Melzack and Wall. They proposed a theory now widely recognized as the gate control theory (Melzack and Wall, 1965). They theorized the activity of large afferent fibers can cause the inhibition of smaller fibers which are generating the nociceptive impulses, for example, the application of an irritating ointment or poultice to produce pain relief. The mechanism by which this process occurs involves inhibitory and excitatory neurotransmitters working in concert.

Each neuron may be influenced by many neurotransmitters which have different actions in a given region. Multiple neurotransmitters may exist within separate intraneuronal vesicles in a single neuron. Both excitatory and inhibitory neurotransmitters are produced, stored, and released in terminals of afferent nerve fibers and dorsal horn neurons. These neurotransmitters are involved in the transmission of nociceptive signals between neurons.

Glutamate and aspartate are the major excitatory neurotransmitters in the central nervous system (CNS). Other important excitatory neurotransmitters include substance $\mathrm{P}$, neurotensin, vasoactive intestinal peptide, and cholecystokinin (Lamont et al., 2000).

GABA is the major inhibitory neurotransmitter in the CNS, being present in many areas including the cerebral cortex and spinal cord. Glycine is the principal inhibitory neurotransmitter in the spinal cord. Serotonin, norepinephrine, and the endogenous opioid peptides (enkephalins, endorphins, and dynorphins) have been identified in dorsal horn neurons and produce inhibitory effects on nociceptive transmission (Cousins and Mather, 1984).

Excitatory neurotransmitters are released in response to activation of the nociceptive pathway by a noxious stimulus. The endogenous opioid system may respond in conjunction 
with other inhibitory neurotransmitters to modulate and decrease the effects of the excitatory neurotransmitters.

\subsubsection{Perception}

Pain is perceived following the successful transduction, transmission, modulation, and processing of nociceptive input at the cerebral level. Pain is a conscious, subjective and emotional experience. Perception of pain in people is influenced by environmental, educational, social, cultural, and individual factors. Determination of an animal's perception of pain remains one of the greatest challenges for the veterinarian. Many species may mask pain as a survival mechanism, or behavior associated with the perception of pain may go unnoticed by an observer. Unlike people, animals cannot verbally quantify the pain they perceive. Veterinarians must rely on physical signals from the animals in their determination of whether the animal is painful.

\subsection{Peripheral Sensitization}

Peripheral sensitization is an increase in sensitivity of A-delta, A-beta and C fibers which enables low intensity stimuli to cause pain. The sensitization occurs as a direct response to the release of inflammatory mediators including bradykinin, serotonin, histamine, potassium ions, and hydrogen ions following tissue trauma and inflammation (Rang et al. 1991). Damage to cells also results in activation of the arachidonic acid pathway and production of prostaglandins and leukotrienes. A combination of the inflammatory mediators and arachidonic acid metabolites act synergistically to convert the high threshold nociceptors to low threshold nociceptors so that the application of low intensity stimuli will now result in receptor activation (Houghton et al. 1997). The perceived pain in response to previously non-painful stimulus is known as allodynia. 


\subsection{Central Sensitization}

Central sensitization refers to the alteration of responses in dorsal horn neurons associated with sustained afferent impulse activity from the summation of action potentials that occurs due to slow synaptic potentials (lasting up to 20 seconds) of A-Delta and C fibers. A progressive, long lasting depolarization in the dorsal horn neurons develops. Just a few seconds of C fiber input can generate several minutes of postsynaptic depolarization. This process is often termed "wind-up" and is mediated by both N-methyl-D-aspartate (NMDA) receptors that bind glutamate and tachykinin receptors that bind substance $\mathrm{P}$ and neurokinin A (Thompson et al. 1990; Woolf and Wall, 1986). Wind-up results in an increase in the second messenger protein kinase (as a result of $\mathrm{G}$ protein receptor activation) which provides positive feedback to the NMDA receptors, thereby increasing their efficacy (Woolf and Chong, 1993). The outcome of central sensitization is hypersensitivity to noxious stimuli and allodynia.

\subsection{Hyperalgesia}

Pathologic pain from tissue trauma causes an increase in sensitivity in areas not adjacent to the nociceptive stimulus or tissue injury. This area of heightened sensitivity is referred to as the zone of secondary hyperalgesia. Secondary hyperalgesia develops with the recruitment of A-beta fibers that are normally associated with specialized, low threshold peripheral mechanoreception. These fibers generate innocuous sensations; but once central sensitization occurs they contribute to nociception. The metabolites of arachidonic acid and bradykinin also play a role in sensitization (Dahl and Kehlet, 1991). Inhibition of peripheral and central sensitization processes is achieved by preemptive analgesia; the initiation of treatment prior to the introduction of noxious stimuli (Woolf and Chong, 1993). 


\subsection{Multimodal Approach to Analgesia}

Multimodal analgesia refers to the clinical practice of combining drugs and routes of administration with other techniques (such as acupuncture) to achieve additive or synergistic effects. For example, pain associated with intervertebral disk disease or invasive soft tissue neoplasias are likely to have both inflammatory and neuropathic components. Effective pain management targets transduction, transmission, perception, and modulation pathways. The major drug categories used in multimodal analgesia include local anesthetics, non steroidal anti-inflammatory drugs, alpha ${ }_{2}$-adrenergic agonists, NMDA antagonists, and opioids. These drugs can be administered in a variety of ways, for example intravenously via a constant rate infusion (NMDA antagonism with Ketamine), or transdermally (fentanyl).

\subsubsection{Local Anesthetics}

Local anesthetics administered topically, intra-dermally, peri-neurally, intrathecally and epidurally act by blocking sodium channels and preventing impulse transmission, they also inhibit modulatory nociceptive processing when administered epidurally or intrathecally (Butterworth and Strichartz, 1990, Brown et al. 1990, and Feldman and Covina, 1988). Local anesthetics are applied directly at the target site and absorption into the systemic circulation is not required for analgesia. These drugs inhibit nociception by blocking the transduction of impulses. Epidural or subarachnoid administration can also inhibit transmission via peripheral nerves or plexuses. Local anesthetic solutions introduced via these routes act on superficial layers of the spinal cord, but the principal site of action is at the preganglionic fibers as they exit the spinal cord.

\subsubsection{Non Steroidal Anti-inflammatory Drugs (NSAIDs)}

The arachadonic acid pathway involves the production of mediators involved in inflammation such as prostaglandins. Enzymes involved in the pathway include 
cyclooxygenase (COX) (which include two isoforms, COX 1 and COX 2) and lipoxygenase (LOX).

NSAIDs inhibit cyclooxygenase and lipoxygenase activity and thus prevent synthesis of prostaglandins (Brooks and Day, 1991) (Figure 1).

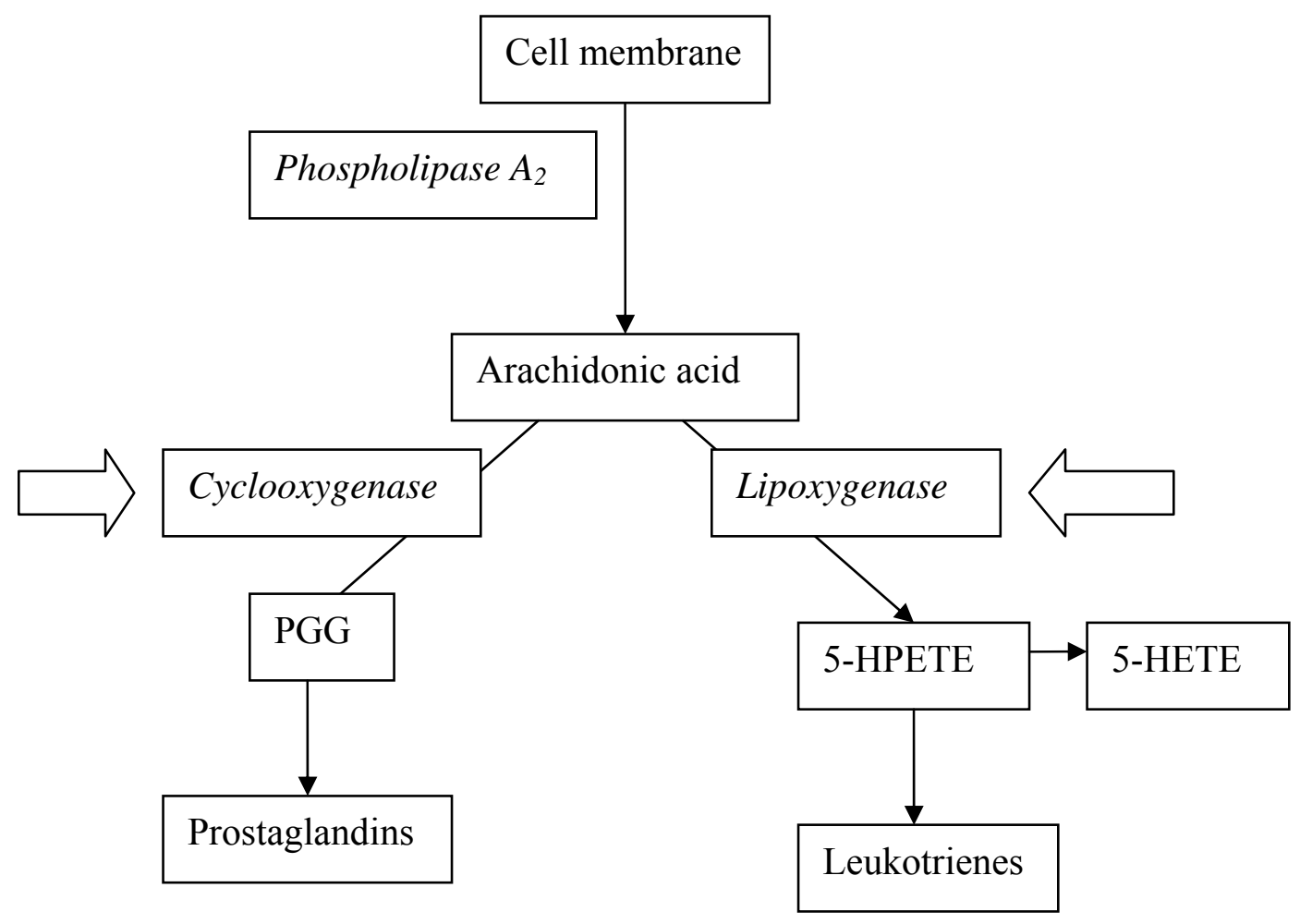

Figure 1. The Arachidonic acid cascade. HPETE = hydroperoxyeicosatetaenoic acid; HETE = hydroxyeicosatetraenoic acid; $\mathrm{PGG}=$ prostaglandin $\mathrm{G}$; large arrow indicates inhibition of enzymes by NSAID.

The decreased production of these alogenic substances i.e. prostaglandins, will obtund transduction. The mechanism of inhibition of cyclooxygenase varies among NSAIDs. Inhibition of prostaglandin synthesis decreases the inflammatory response to surgical trauma.

Preoperative administration can decrease postoperative pain and requirements for opioids (Souter et al., 1994) but it is important to note that renal blood flow depends on prostaglandins for release of renin (especially if blood volume is reduced) and 
recommendations have been made to withhold NSAIDs prior to surgery because of the risk of renal impairment (Clive and Stoff, 1984).

Adverse reactions to NSAIDs are common including gastrointestinal effects such as erosions, renal effects such as tubular necrosis, coagulation effects as a result of alterations in platelet aggregation, and interactions with other drugs.

\subsubsection{Alpha 2 -adrenergic Agonists}

Alpha 2 -adrenergic agonists bind to 3 receptor types referred to as $\alpha_{2 \mathrm{a}}, \alpha_{2 \mathrm{~b}}$, and $\alpha_{2 \mathrm{c}}$ (Bylund et al. 1994). These receptors are distributed throughout the body, including the dorsal horn of the spinal cord (site responsible for analgesic actions) and the locus coeruleus of the brain stem (site responsible for sedative effects) (Correa-Sales et al. 1992). The $\alpha_{2 a}$ receptors mediate sedation, hypnosis, analgesia and sympatholysis (Lakhlani et al. 1997 $\mathrm{Alpha}_{2}$-adrenegic agonists modulate the release of substance $\mathrm{P}$ and other neurotransmitters involved in nociception possibly via interactions with other receptors such as opioid and cholinergic. The positive impact on modulation of nociceptive transmission using this class of drugs is beneficial in multimodal pain management.

\subsubsection{N-methyl-D-aspartate Antagonists}

Ketamine (a phencyclidine derivative) is a non competitive antagonist of the NMDA glutamate receptor (Lodge and Anis, 1982). Ketamine also interacts with the phencyclidine binding receptor which causes inhibition of activity at the NMDA receptor. The action of ketamine at receptor sites in the dorsal horn prevents central sensitization (Stubhaug et al 1997). Administration can be intramuscularly, intravenously, (bolus or continuous rate infusion), epidurally, or topically (Kronenburg, 2002).

\subsubsection{Opioids}

Opioid descibes all exogenous substances that bind to opioid receptors and produce an agonistic (morphine-like) effect. Opioids may be naturally occurring (morphine), 
synthetic (methadone) or semi-synthetic (fentanyl). Opioids are characterized based on specific receptor activity as agonists e.g. fentanyl, or agonist/antagonists e.g. butorphanol. Morphine is the prototype opioid and offers comparisons to other opioids.

\subsection{Opioid Receptors}

\subsubsection{Classification and Distribution of Opioid Receptors}

Opioid receptors are classified as mu, delta and kappa receptors (Atcheson and Lambert, 1994). The original classification established in the 1970's was based on the response patterns in the chronic spinal dog model to three different opioid compounds (Martin et al. 1976). The receptors were named after the drugs used in this original study: mu (morphine), kappa (ketacyclazocine), and sigma (SKF 10,047). Subsequently, it has been determined that the sigma receptor is not an opioid receptor but rather a high affinity binding site for phencyclidine and similar compounds (Pleuvry, 1991). In 1977, a binding site in the mouse vas deferens that had a high affinity for enkephalins was identified and named delta receptor (Takemori et al. 1986). Epsilon receptors were also identified in the rat vas deferens but are no longer considered opioid receptors. Attempts to detect epsilon opioid receptors in tissue other than the rat vas deferens have been unsuccessful (Contet et al. 2004). More recent advances in molecular cloning have led to the renaming of these receptors as OP1 (delta), OP2 (kappa), OP3 (mu), and ORL1 (opioid like receptor 1), (Singh et al. 1997). The ligand for ORL1 is orphanin FQ/nociceptin (Meunier, 1997). Early work suggests that this receptor is widespread but the exact nature of its functions remain controversial at this time (Kieffer, 1995). An interplay with the endogenous opioid system has been suggested (Grisel and Mogil, 2000; Reinscheid et al., 2000). The endogenous opioid system is activated by three endogenous peptide opioid receptor ligands referred to as enkephalins, endorphins, and dynorphins (Atcheson and Lambert, 1994). 
Two subpopulations of mu receptors are responsible for either analgesia $\left(\mathrm{mu}_{1}\right)$ or side effects such as hypoventilation, bradycardia, and physical dependence $\left(\mathrm{mu}_{2}\right)$. Endorphins act on the $\mathrm{mu}_{1}$ receptors. Kappa agonists, such as dynorporhin, produce less respiratory depression, but high intensity painful stimuli may be resistant to the effects of these substances. Some opioid agonist-antagonists such as butorphanol act mainly on these kappa receptors. Delta receptors respond to enkephalins and may be more important in spinal analgesia. They may modulate the activity of mu receptors.

Until the late 1980's opioids were believed to act predominantly centrally but it has become clear that opioid receptors are also present in the peripheral nervous system (Stein, 1995).

\subsubsection{Cellular Mechanisms}

Opioid receptors are a subset of $\mathrm{G}$ protein-coupled receptors that include muscarinic receptors and somatostatin receptors. Amino acid sequences in opioid receptors demonstrate considerable homology with somatostatin receptors but not with other receptors in this group. Opioids have direct (presynaptic) and indirect (post synaptic) effects (Yaksh, 1997; Trafton et al., 2000). Opioid receptor activated G protein effector systems have short term effectors such as potassium and calcium ion channels which result in rapid but short lasting effects and long term effector systems involving second messengers such as cyclic adenosine monophosphate (cAMP) responsible for more slowly occurring but longer lasting effects. Changes in cAMP are able to modulate the release of other important neurotransmitters such as substance P (Stein 1995). All opioid receptors prevent the opening of voltage dependent calcium channels, decreasing neurotransmitter mobilization and release.

$\mathrm{Mu}$ receptor agonists possess a similar set of effects but may vary in degree of effect (table $1)$. 


\subsection{Fentanyl}

Fentanyl is a pure mu receptor agonist considered to be 75 to 125 times more potent than morphine. Fentanyl (N-Phenyl-N-(1-2-phenylethyl-4-piperidyl) propanimide) is a synthetic phenylpiperidine derivative structurally related to meperidine. The empirical formula for fentanyl is $\mathrm{C}_{22} \mathrm{H}_{28} \mathrm{~N}_{2} \mathrm{O}$ (figure 2).

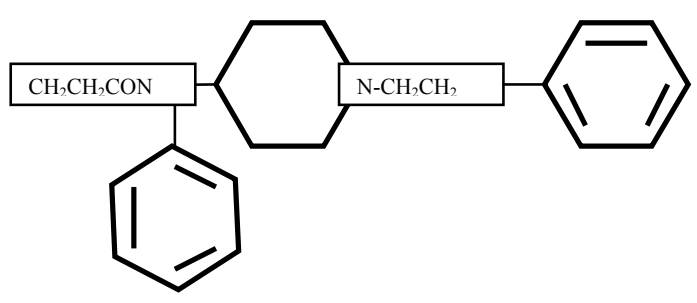

Figure 2. The chemical structure of fentanyl

\subsubsection{Routes of Administration}

Fentanyl is normally administered via intravenous injection, as a bolus or as a continuous rate infusion. Transmucosal delivery is possible and is especially useful for relieving preoperative anxiety and facilitating a smooth anesthetic induction in children (Zeltzer et al., 1989). Transmucosal fentanyl is administered in the mouth via a attached to a handle (Feld et al., 1989; Macaluso et al., 1996; Stanley et al., 1989). Administration of transdermal fentanyl via a patch adhered to the skin is used in people and various species.

\subsubsection{Pharmacokinetics}

Fentanyl is highly lipid soluble with a rapid onset of action following intravenous administration. Lipid solubility facilitates the passage of the drug across the blood brain barrier. The short duration of action of fentanyl reflects the rapid redistribution of fentanyl to inactive sites such as muscle and fat, with an associated decrease in plasma concentrations (Hug and Murphy, 1981). Seventy five percent of the initial intravenous dose of fentanyl undergoes first pass pulmonary uptake (Roerig et al. 1987). The lungs act as a large inactive storage site and limit the initial amount of drug that reaches the systemic circulation. 
Table 1. Effects of short- and long-term administration of opioids

\begin{tabular}{|c|c|}
\hline Administration of Opioids & Effects \\
\hline Short-term & $\begin{array}{l}\text { Analgesia } \\
\text { Respiratory depression } \\
\text { Sedation } \\
\text { Euphoria } \\
\text { Vasodilation } \\
\text { Bradycardia } \\
\text { Cough suppression } \\
\text { Miosis } \\
\text { Nausea and vomiting } \\
\text { Skeletal muscle hypertonus } \\
\text { Constipation } \\
\text { Urinary retention } \\
\text { Biliary spasm }\end{array}$ \\
\hline Long-term & $\begin{array}{l}\text { Tolerance to effects of drug } \\
\text { Physical dependency }\end{array}$ \\
\hline
\end{tabular}

In the presence of continuous delivery of fentanyl there is progressive saturation of inactive sites resulting in protracted clearance and sustained plasma concentrations of the drug.

After intravenous administration fentanyl demonstrates an extensive extravascular volume of distribution, a medium to high total body clearance, and a low renal clearance. There are large variations in reported pharmacokinetics of fentanyl (Grond et al. 2000). Such variations are produced by variation in the fentanyl assays used, the pharmacokinetic models, and route of administration.

The presence of fentanyl in the systemic circulation after transdermal application is determined not only by skin permeability, but also by local blood flow. Only extreme variations in blood supply influence fentanyl absorption (Grond et al. 2000).

In dogs and cats there is considerable interspecies variation in both the time to achieve steady state concentrations (consistent concentrations over time) and durations of action following application of a TDF patch. In dogs, steady state plasma concentrations are 
reached after 24 to 36 hours (Egger et al. 1998; Kyles et al. 1996). In cats steady-state plasma concentrations are reached after 2 to 18 hours (Scherk-Nixon, 1996; Lee et al. 2000). The time to steady state plasma fentanyl concentrations is influenced by the rate of drug release from the patch, absorption of drug across the epidermis and dermis, uptake by cutaneous vasculature and patient volume of distribution and clearance.

Following removal of a transdermal fentanyl patch there is a gradual drop in serum fentanyl concentrations due to ongoing absorption from the skin depot. A gradual decline in plasma fentanyl concentration to $50 \%$ of previous concentrations after approximately 17 hours was observed in dogs (Varvel et al. 1989). Other reports indicate the terminal half life of the drug to be 13 to 15 hours (Broome et al. 1995). Thus beneficial effects of the drug may be evident even after removal of the patch, however, there is also potential for adverse affects such as respiratory depression.

Bioavailability of fentanyl during transdermal administration can be calculated by dividing the plasma concentration by the amount of drug absorbed from the transdermal patch. Varvel et al. (1989) demonstrated that $92 \%$ of the fentanyl dose being administered transdermally reaches the systemic circulation as unchanged fentanyl, indicating that fentanyl biotransformation during transdermal penetration is negligible (8\%).

Upon removal of a patch, considerable drug still remains unused. In humans, following 72 hours of application, between 28 and $85 \%$ of the original fentanyl content still remains in patches (Marquardt et al. 1995). Cases of abuse of fentanyl remaining in TDF patches have been documented in the human literature; the potential for abuse is no less real in veterinary medicine and caution should be exercised when prescribing TDF for home administration. 


\subsubsection{Metabolism}

Fentanyl is metabolized by $N$-demethylation in the liver. The metabolite norfentanyl is excreted by the kidneys and can be detected in urine for 72 hours following a single intravenous injection. Compared to morphine, fentanyl has a longer elimination half time (i.e. the time taken for serum fentanyl concentrations to decrease to $50 \%$ of the peak serum concentration) due to the larger volume of distribution of fentanyl (both morphine and fentanyl have similar clearance rates). The larger volume of distribution of fentanyl is because it is more lipid soluble and subsequently has a more rapid movement into tissues.

\subsubsection{Pharmacodynamics}

The interaction of a drug with a specific protein molecule (or receptor) in the lipid bilayer of cell membranes is one of the most important ways in which a drug exerts pharmacologic effects. Fentanyl interacts primarily with the mu opioid receptor. Opioid receptors are located at pre and post synaptic sites throughout the central nervous system and in peripheral tissues. Intracellular events that follow activation of the mu opioid receptor include increased potassium conductance and calcium channel inactivation via $\mathrm{G}$ proteins, the ensuing hydrolysis of guanine triphosphate (GTP) to guanine diphosphate (GDP) releases energy which is then used by the activated $\mathrm{G}$ protein to interact with effector systems (such as potassium ion channels) resulting in recognizable clinical results such as analgesia (Atcheson and Lambert, 1994). An immediate decrease in neurotransmitter occurs mainly as a result of presynaptic inhibition of neurotransmitter release (de Leon-Casasola and Lema, 1993), although postsynaptic inhibition can also occur (Atcheson and Lambert, 1994).

The concentration of fentanyl required to obtain a certain analgesic effect depends on several factors including the intensity of the pain, and receptor regulation. 


\subsubsection{Antagonism}

Very small changes in the structure of an opioid can result in the formation of an opioid antagonist (Glass et al. 1994). The substitution of an alkyl group for a methyl group on an agonist is a common change employed to manufacture an opioid antagonist.

Naloxone, naltrexone, and nalbuphine are pure mu antagonists (i.e. their administration results in displacement of the agonist from the receptor). These drugs have a very high affinity for mu opioid receptors.

Partial antagonism can also be achieved by using an agonist-antagonist drug such as butorphanol. Butorphanol is an agonist at the kappa receptor but antagonist at the mu receptor (Vandam, 1980). Utilization of this type of antagonism may confer some degree of analgesia (mediated by the kappa receptor in this example) (Lemke et al. 1996; McCrackin and Harvey, 1992; Dyson et al. 1990; Bowdle, 1987).

\subsection{Transdermal Fentanyl}

Transdermal fentanyl patches were introduced to the veterinary market in 1991 and are marketed under the trade name Duragesic ${ }^{\circledR}$. Four doses are available; $25 \mu \mathrm{g} / \mathrm{h}, 50 \mu \mathrm{g} / \mathrm{h}$, $75 \mu \mathrm{g} / \mathrm{h}$, and $100 \mu \mathrm{g} / \mathrm{h}$, with corresponding patch sizes of $10,20,30$, and $40 \mathrm{~cm}^{2}$, respectively.

Fentanyl is suitable for transdermal administration because of its physiochemical properties (such as lipophilicity and molecular weight) and its high analgesic potency (requiring only small volumes) (Bailey et al., 2000). The skin normally acts as a barrier and protects the body from injury. In order for any drug to permeate the intact skin, it must have a low molecular weight $(\leq 1000 \mathrm{~g} / \mathrm{mol})$ and high solubility in oil (Grond et al. 2000). Fentanyl has a molecular weight of $289 \mathrm{~g} / \mathrm{mol}$ and is highly lipophilic (Grond et al. 2000). The skin flux of fentanyl is about 1000 times greater than morphine in human cadaver skin (Roy and Flynn, 1989). 


\subsubsection{Components of a Transdermal Fentanyl Patch}

The transdermal delivery system or patch is composed of four functional layers and a protective liner. The first protective layer is removed immediately prior to application of the patch. The next layer is a silicone adhesive layer that contains fentanyl and allows free diffusion which delivers an initial bolus upon application. The third layer is a rate limiting ethylene-vinyl acetate copolymer membrane which limits the diffusion of fentanyl from the drug reservoir behind the membrane. The drug reservoir also contains a small amount of alcohol $\left(0.1 \mathrm{ml}\right.$ per $\left.10 \mathrm{~cm}^{2}\right)$ which acts as an absorption enhancer by increasing vasodilation, therefore reducing variation in absorption. The fentanyl and alcohol are gelled with hydroxyethyl cellulose. The final outermost layer is a polyester film which prevents escape of the fentanyl into the environment. (Figure 3)

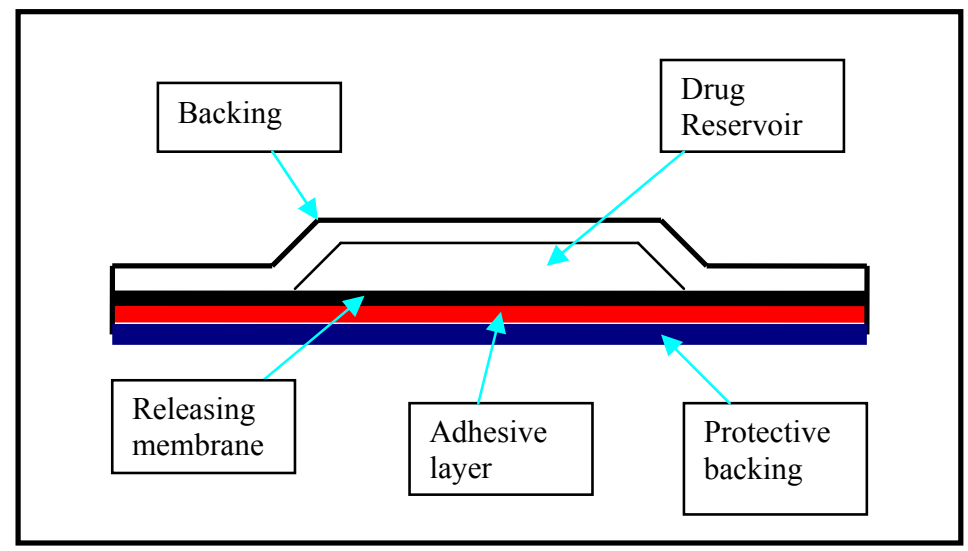

Figure 3. Transdermal fentanyl patch

\subsubsection{Application of a Transdermal Fentanyl Patch}

Haired areas should be clipped with scissors (not shaved), cleansed and allowed to dry prior to application of the patch. This prevents potential irritation that may be caused by clippers, which could increase absorption of the drug (Gilberto et al. 2003). The patch is usually applied to areas on the thorax or dorsum. Alterations in absorption have been observed when patches are placed in areas that have thinner skin such as the inguinal area (in 
dogs). The application of an adhesive wrap or light bandage may be of benefit to prevent the patch from being removed by the animal. It is not recommended to glue or staple patches in place. Care must also be taken to prevent inadvertent heating of the area in the proximity of the patch as absorption could be greatly enhanced resulting in a potential overdose.

Absorption of transdermal fentanyl may also be altered by variations in blood flow, state of hydration, skin and body temperatures (Kyles, 1998; Kyles et al., 1996).

\subsubsection{Plateau Serum Fentanyl Concentrations Following Application}

In people, serum fentanyl concentrations during transdermal administration reach a plateau approximately 36 hours after application of the patch (Gourlay et al. 1989), in dogs 24 hours (Egger et al. 1998; Kyles et al. 1997; Schultheiss et al. 1995; Robinson et al. 1999), in horses 4 hours (Matthews et al. 1997), and in cats, from 2 to 18 hours (Franks et al. 2000). There is considerable variation in the terminal half life of the drug after removal of the patch. It takes up to 17 hours in people for terminal half life to be reached (due to continued absorption from a peripheral reservoir believed to be in the stratum corneum) (Varvel et al. 1989). Concentrations slowly decrease as fentanyl stored in inactive tissue sites such as fat, skeletal muscles and the lungs are depleted (Hug and Murphy, 1981; Roerig et al. 1987). In dogs, a mean of 99 minutes is reported (Kyles et al. 1996). The longer terminal half life in people is the result of saturation of cutaneous fat that continues to release fentanyl after removal of the patch.

\subsubsection{Side Effects}

\subsubsection{Cardiovascular}

Unlike other naturally occurring opioids, fentanyl does not cause release of histamine, even at high doses, therefore hypotension as a result of dilation of venous capacitance vessels is unlikely to occur (Roscow et al. 1982). Fentanyl will depress baroreceptor reflex control of heart rate more than morphine (Murat et al. 1988). Subsequent 
reductions in heart rate may occasionally result in hypotension, especially in neonates normotension is primarily heart rate dependant. (Murat et al. 1988).

\subsubsection{Respiratory}

People are particularly sensitive to opioid mediated respiratory depression (Becker et al. 1976) and transdermal administration of fentanyl in the post-operative period is contraindicated. Significant post-operative hypoventilation is not observed in dogs despite the delivery of relatively high doses of fentanyl from the transdermal system (average $4.8 \mu \mathrm{g} / \mathrm{kg} / \mathrm{hr}$ ) (Welch et al. 2002).

\subsubsection{Non Cardiopulmonary}

Gastrointestinal effects of opioids include spasms of the gastrointestinal smooth muscle which decreases peristalsis and enhanced tone of the pyloric sphincter (Allescher et al., 1988; Smith et al., 2004; Bayguinov and Sanders, 1993). Constipation associated with decreased peristalsis and prolonged transit time of ingesta is observed in people but not in small animals.

Vomiting is caused by direct stimulation of the chemoreceptor trigger zone in the area of the postrema of the medulla, possibly through delta receptors (Watcha and White, 1992).

Increases in urine production may be associated with decreases in production of antidiuretic hormone and atrial natriuretic peptide (Pesonen et al. 1990). The incidence of urinary retention varies and is likely due to an interaction of the opioid with the opioid receptors in the sacral spinal cord (Rawal et al. 1983). It is more common with neuraxial opioids than intravenous or intramuscular. The interaction inhibits sacral parasympathetic nervous system outflow resulting in relaxation of the detrusor muscle and an increase in bladder capacity. With systemic opioid administration urinary urgency is a result of 
augmentation of the detrusor muscle tone but enhanced sphincter tone making voiding difficult.

\subsubsection{Therapeutic Uses in Veterinary Medicine}

Fentanyl is used across species, intravenous low doses $(1-2 \mu \mathrm{g} / \mathrm{kg})$ for analgesia, or higher doses $(50-150 \mu \mathrm{g} / \mathrm{kg})$ with other agents for anesthesia.

In dogs undergoing major orthopedic surgery, transdermal fentanyl provided equal or greater analgesia than did epidural morphine (Robinson et al. 1999). In cats undergoing onychectomy, transdermal fentanyl allowed cats better recovery scores, lower sedation scores, and lower pain scores than did intravenous butorphanol (Franks et al. 2000).

Recent work by Pettifer et al. in hypothermic and normothermic cats evaluated perianesthetic serum fentanyl concentrations with transdermal fentanyl administration. Hypothermic anesthetized cats had significantly lower serum fentanyl concentrations compared to normothermic anesthetized cats, although concentrations remained within the range believed to confer analgesia (Pettifer and Hosgood, 2003). Similar findings are reported in dogs (Pettifer and Hosgood, 2004). The impact of alterations in fentanyl concentrations on intra-operative analgesia and any anesthetic sparing effects of fentanyl is undetermined.

\subsection{Evaluation of Analgesia during General Anesthesia}

Recent investigations have documented a decrease in the serum fentanyl concentrations in hypothermic dogs and cats compared to normothermic dogs and cats during inhalant anesthesia in the presence of transdermal fentanyl (Pettifer and Hosgood, 2003; Pettifer and Hosgood 2004). Whether the decreased fentanyl concentration alters inhalant requirements during anesthesia is not known. Investigation to assess alterations in inhalant anesthetic requirements would require determination of the minimum alveolar 
concentration (MAC) of the inhalant and comparison to the MAC in hypothermic and normothermic animals receiving transdermal fentanyl.

\subsection{Minimum Alveolar Concentration}

The concept of minimum alveolar concentration (MAC) was originally described in 1963 by Merkel and Eger to provide a repeatable method of measuring and comparing anesthetic potencies. MAC was originally defined as the minimal alveolar concentration of inhalant in the alveoli required to prevent a dog from responding to a painful stimulus. Subsequently MAC for people was defined as the point at which 50 per cent of the patients moved in response to a skin incision (Saidman and Eger, 1964). Determination of MAC requires measuring the end tidal concentration of inhalant which is considered representative of the alveolar concentration. When an anesthetic gas is inhaled it will diffuse down its concentration gradient from the alveoli into the arterial blood and then across the blood brain barrier until equilibrium is established. Once equilibrium is established, the end tidal concentration of inhalant should equal the concentration of the inhalant in the brain.

\subsubsection{Determination of the Minimum Alveolar Concentration of an Anesthetic}

Two models are used to determine MAC. The first is the quantal study design used in people. In this model, each person is exposed to a constant anesthetic concentration for a set time determined by the inhalant being investigated prior to application of a noxious stimulus such as skin incision. Presence or absence of movement is noted. The resulting quantal information (presence or absence of movement for each person at the different inhalant concentrations) is then fit to either a logistic or sigmoid Emax equation and MAC is calculated (Sonner, 2002). The second model employs a bracketing technique. This method is often used in animal experiments. An animal is exposed to a constant anesthetic concentration, a noxious stimulus is applied, and the presence or absence of movement is noted. If an animal moves at the observed concentration, the anesthetic concentration is 
incrementally increased and the procedure repeated until no movement occurs. The MAC is then determined to be the value midway between the concentration at which movement occurred and the concentration at which no movement occurred.

The noxious stimulus used should be reproducible, and provoke a predictable movement. If the stimulus cannot be measured, it should be supramaximal to avoid any variation in response attributable to variation in stimulus. End tidal inhalant anesthetic concentration is measured and considered equivalent to the anesthetic concentration in the brain.

\subsubsection{Supramaximal Stimulation}

All MAC studies are conducted using supramaximal stimulation. Supramaximal stimulation refers to the point beyond which increasing stimulus intensity will not increase MAC (Quasha et al. 1980). In people the noxious stimuli used is surgical skin incision. The supramaximal stimulation most commonly used in animals is clamping the tail with a hemostat i.e. forcep for 30 to 60 seconds. Electrical stimulation of the limbs, cheek or sensitive mucosa has also been used $(30-50 \mathrm{~V}$ at 50 cycles/second for 10 milliseconds). A study comparing electrical stimulation versus tail clamp in rats concluded that electrical stimulation provided an equivalent stimulus (Laster et al. 1993). Several types of supramaximal stimuli have been validated in dogs and rabbits including tail clamp and electrical stimulation (Valverde et al. 2003).

\subsubsection{Determination of MAC in Dogs}

Following induction of anesthesia, the dog is allowed to stabilize at a chosen end tidal gas concentration held constant for 15 minutes. Fifteen minutes for equilibration is based on the assumption that there is a cerebral blood flow of $50 \mathrm{ml} / 100 \mathrm{~g} / \mathrm{minute}$ (Kety and Schmidt, 1945) and a brain:blood partition coefficient of 2.5 or less. If these assumptions are met, then 15 minutes allows for at least 95 per cent equilibration between arterial and brain 
tensions of the agent (Eger et al. 1965). The end-tidal inhalant concentration is noted and a supramaximal stimulus applied. The dog is observed for any gross purposeful movement i.e. movement of the head or trunk. Swallowing, coughing, or chewing motions are not considered purposeful movement since they may be reflex responses not requiring consciousness. If no movement occurs, the inhalant is decreased to 80 or 90 percent of the original concentration and 15 minutes is allowed for gas equilibration before reapplying the stimulus. If movement occurs at this lower concentration, the concentration is increased in forward and backward increments and stimulation is repeated until the observer can narrow the range between the concentration at which occurs and the concentration at which there is no movement. The MAC is taken as the mid point between these two concentrations. If, on the initial stimulation, there is movement, the inhalant concentration is increased by 10 to 20 $\%$ and the process repeated as before until no movement is observed. The smaller the incremental increase and decreases, the more accurate the determination of MAC will be. Although MAC is considered a characteristic of the inhalant, many drugs and other factors can impact MAC (Table 2), (Stanski et al. 2000; Quasha et al. 1980).

\subsection{Thermoregulation}

Body temperature is a function of heat production and loss. Heat is produced in the body as a by-product of metabolism, however heat is continuously being lost to the environment. Body temperature in mammals shows a circadian variation corresponding to decreased activity and reduced metabolic rate during sleep. Control of body temperature (thermoregulation) occurs via feedback through the nervous system to the preoptic nucleus of the anterior hypothalamus (Sessler et al. 2000). A decrease in body temperature causes stimulation of the posterior hypothalamic sympathetic centers with a resulting increase in circulating nor epinephrine resulting in vasoconstriction of cutaneous blood vessels, thereby decreasing the amount of heat lost from the skin surface. Other heat sensing areas are also 
Table 2. Factors that affect minimum alveolar concentration

\begin{tabular}{|l|l|}
\hline Effect on MAC & Factors \\
\hline Decrease & Hypothermia \\
& Severe hypotension \\
& Age \\
& Narcotics \\
& Ketamine \\
& Benzodiazepines \\
& Barbiturates \\
& Amphetamines \\
& Reserpine \\
& Methyldopa \\
& Cholinesterase inhibitors \\
& Intravenous local anesthetics \\
& Pregnancy \\
& Hypoxemia \\
& Anemia \\
& Alpha 2 -agonists \\
\hline Increase & Hyperthermia \\
& Hyperthyroidism \\
& Alcoholism \\
& Dextroamphetamine \\
\hline No effect & Duration of anesthesia \\
& Sex \\
& Metabolic acid -base status \\
& Hypercarbia \\
& Hypocarbia \\
& Isovolemic anemia \\
& Hypertension \\
\hline
\end{tabular}

present in the midbrain, brainstem, spinal cord, skeletal muscles, and abdominal organs which also play a role in immediate responses to alteration in temperature (Imrie and Hall, 1990).

\subsection{Effect of General Anesthesia on Thermoregulation}

During the first hour of anesthesia the average person will have a $1-1.5^{\circ} \mathrm{C}$ drop in core body temperature, with a further decrease of $1-1.5^{\circ} \mathrm{C}$ over the next one to two hours, followed by a stabilizing of the temperature (Sessler, 1997) The initial decrease in body 
temperature is referred to as the redistribution phase, the second decrease as the linear phase, and the stable period as the core body temperature plateau. (Figure 4)

Upon initiation of general anesthesia, peripheral vasodilation allows the core body heat to move down a temperature gradient to more peripheral tissues. This is not a loss of heat, but a redistribution of heat resulting in a decrease in core body temperature. Redistribution accounts for up to $80 \%$ of the initial decrease in core body temperature during the first hour of anesthesia. The second phase is a slow linear decrease in core temperature which is the result of heat loss in excess of heat production. Heat loss during the linear phase occurs via radiation, conduction, convection, and evaporation and is somewhat dependant on event.

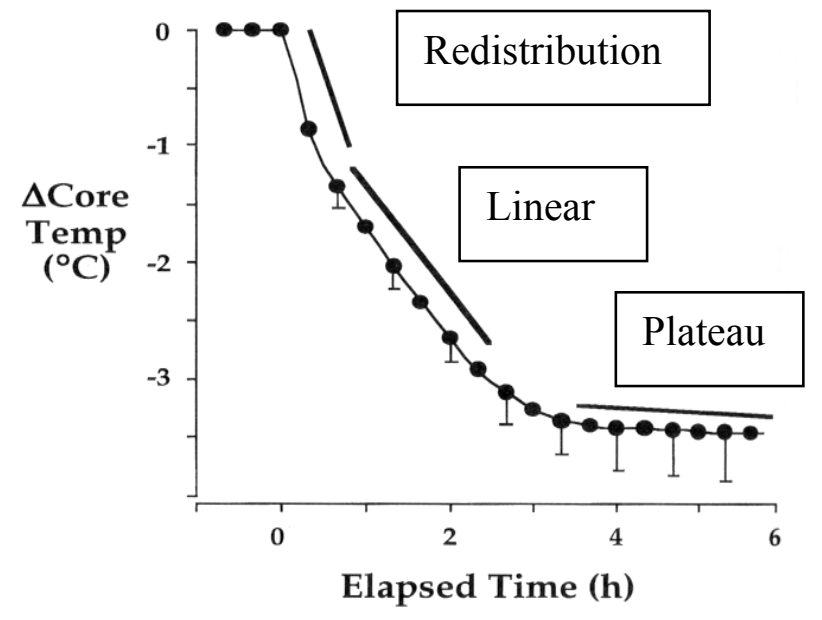

Figure 4. Decrease in temperature during general anesthesia

The final plateau phase occurs after two to three hours of anesthesia and is characterized by a constant core body temperature. The plateau is described as either 1 . Passive or 2. Active. 1. The passive plateau occurs when metabolic heat production equals heat loss; this is rarely the case in a normothermic anesthetized animal since heat production is decreased, while loss is increased. 2. An active plateau occurs when a thermoregulatory 
response is triggered which causes vasoconstriction. In people, a core body temperature of 33 to $35^{\circ} \mathrm{C}$ is necessary for activation of this response (Sessler, 2000).

\subsubsection{Influence of Temperature on MAC}

Hypothermia is common in subjects undergoing anesthesia and surgery. This is due to a cool operating room environment, exposure of body cavities, and the impairment of the thermoregulatory control by the anesthetic agent.

The effect of hypothermia in reducing anesthesia requirements has been studied extensively. The average change in isoflurane requirements for each $1^{\circ} \mathrm{C}$ decrease in temperature is between 2-6 percent of MAC in dogs (Quasha et al. 1980).

There is limited information on the effect of transdermal fentanyl and hypothermia on anesthetic inhalant requirements in cats and dogs. Yackey et al. found that there was a statistically significant reduction in MAC cats with a transdermal fentanyl. This study also noted that serum fentanyl concentrations peaked during the MAC study, possibly due to the use of external warming devices, or changes in peripheral circulation which occur with inhalant anesthesia (Yackey et al. 2004). In order to appreciate the alterations which occur in the peripheral circulation associated with inhalant anesthetics, a review of the normal determinants of tissue blood flow and how blood flow to the tissues is controlled is useful.

Tissue blood flow is determined by blood pressure and the resistance in the vessels of the tissue. The relationship between pressure and resistance can be expressed by Ohm's law, in which blood flow (amperes) is directly proportional to the pressure difference across two points (voltage) and inversely proportional to resistance. (Figure 5) It should be noted that resistance to blood flow cannot be measured directly but is calculated from the driving pressures and cardiac output. $(\mathrm{R}=1333 \mathrm{X} \mathrm{mmHg} / \mathrm{CO}(\mathrm{ml} / \mathrm{sec}))$. 


\section{Pressure Difference Between}

Two points $(\Delta \mathrm{P})$

Blood Flow $=$

(Q)

Resistance to Flow (R)

$$
\begin{aligned}
& \Delta \mathrm{P}=\mathrm{Q} \times \mathrm{R} \\
& \mathrm{R}=\Delta \mathrm{P} / \mathrm{Q}
\end{aligned}
$$

Figure 5. The relationship between blood flow $(\mathrm{Q})$, pressure differential $(\Delta \mathrm{P})$, and resistance to flow $(\mathrm{R})$ can be expressed by Ohm's law.

\subsection{Autoregulation of Blood Flow}

Acute autoregulation allows a specific tissue to maintain a relatively constant blood flow over a wide range of mean arterial pressures. The response occurs within 60 to 120 seconds in response to sudden changes in pressure.

Two theories have been proposed to explain how autoregulation occurs. The metabolic theory describes an increase in mean arterial blood pressure increasing blood flow and the delivery of nutrients etc.; vasodilatory substances (such as endothelin-derived relaxing factor) are flushed out. These conditions result in blood vessels constricting. Conversely, a decrease in blood pressure decreases blood flow and therefore the delivery of nutrients and vasodilating substances remain, thus vasodilation occurs. The myogenic theory describes increases in blood pressure resulting in sudden stretch of small blood vessels, which in turn causes the smooth muscle of the vessel walls to contract thereby reducing the flow back towards normal.

\subsection{Effects of Hypothermia on Tissue Blood Flow}

Thermoregulatory vasoconstriction occurs when integrated thermal inputs from the skin surface, neuroaxis and deep tissues reach a threshold of activation. In the nonanesthetized subject, physiologic responses to external cold include vasoconstriction, shivering, nonshivering thermogenesis, and piloerection. Anesthetic agents interfere with normal physiologic responses such as vasoconstriction by depressing the central threshold 
for peripheral vasoconstriction. Isoflurane decreases the threshold by $3^{\circ} \mathrm{C}$ per percent endtidal volume of anesthetic (Støen et al. 1990). By promotion of peripheral vasodilation (as opposed to the expected vasoconstriction) heat loss is increased. At a core body temperature of about $34.5^{\circ} \mathrm{C}$ and in the absence of ongoing active cooling, vasoconstriction occurs (mainly of the hands and feet in people). This vasoconstriction decreases ongoing heat loss by approximately $25 \%$ and results in a temperature plateau being established (Sessler et al. 1990). The increase in peripheral vasodilation could result in decreased amounts of fentanyl being absorbed from a transdermal patch which could in turn reduce the availability of fentanyl at the biophase.

\subsection{Effects of Isoflurane on Tissue Blood Flow}

Inhaled anesthetics produce marked changes in cardiovascular function including changes in heart rate, myocardial contractility, cardiac output, and systemic vascular resistance. Peripheral circulatory effects are dose dependant and specific for each anesthetic. Isoflurane increases heart rate and decreases systemic vascular resistance when administered to healthy people (Cahalan et al. 1987). Decreases in systemic vascular resistance during administration of isoflurane principally reflect substantial increases in skeletal muscle blood flow (Stevens et al. 1971). Cutaneous blood flow is also increased by isoflurane. Implications of these alterations in blood flow may include wasted perfusion relative to oxygen needs, enhanced delivery of drugs to the neuromuscular junction, enhanced uptake of drugs administered transdermally, and the loss of body heat and development of mild to moderate hypothermia due to increased cutaneous blood flow.

\subsection{Transdermal Fentanyl Concentrations during Anesthesia}

Transdermal fentanyl is an option for the perioperative management of many species including cats and dogs. Intra-anesthesia hypothermia has been documented to decrease fentanyl concentrations. Any change in the anesthetic sparing effect of transdermal fentanyl 
during anesthesia has not been evaluated in dogs. If reductions in serum fentanyl concentrations are the result of decreased uptake of fentanyl from the dermal depots, then anesthetic sparing effect of fentanyl will be lessened. However, if reductions in fentanyl concentrations are due to a shift of the drug into the biophase, then any anesthetic sparing effect should be maintained.

\subsection{Hypothesis and Objectives for Study}

The objectives of this investigation were to determine: (i) if the minimum alveolar concentration of isoflurane would be different between normothermic compared with hypothermic dogs with transdermal fentanyl; (ii) the magnitude of any change in isoflurane requirements during moderate hypothermia; (iii) if there was any interaction between the effects of body temperature and transdermally administered fentanyl on the minimum alveolar concentration of isoflurane in dogs. We hypothesized that the MAC of isoflurane would be lower in normothermic dogs with transdermal fentanyl and hypothermic dogs when compared to normothermic dogs with no TDF. In addition we also hypothesized the MAC for hypothermic dogs receiving transdermally administered fentanyl would not be different from that of hypothermic dogs not receiving transdermal fentanyl. 
CHAPTER 3. MATERIALS AND METHODS 


\subsection{Animals}

This investigation was approved by the Institutional Animal Care and Use Committee, Louisiana State University. Six healthy mixed breed dogs (2 males, 4 females) with a mean $\pm \mathrm{SD}$ weight of $26.0 \pm 3.54 \mathrm{~kg}$ were used. Normal health status was described by a general physical examination, complete blood count and biochemical profile performed prior to the investigation. The dogs were housed in a climate controlled building (temperature range $70-80^{\circ} \mathrm{F}$ ) with light provided between 6 am and $6 \mathrm{pm}$. The dogs were fed a commercially available dog food (Prolab Canine 1600, PMI Feed Inc., St Louis, MO 63144) ad libitum.

All dogs received 4 treatments in random order: 1. sham patch- normothermia (C-NORM), 2. sham patch-hypothermia (C-HYPO), 3. fentanyl patch-normothermia (F-NORM), 4. fentanyl patch-hypothermia (F-HYPO). Random order was determined for each dog by drawing the treatment order from a hat. There was a minimum of 14 days between each trial.

Twenty-four hours prior to anesthesia induction, either a sham patch or a $75 \mu \mathrm{g} / \mathrm{hr}$ fentanyl patch (Duragesic, Janssen Pharmaceutica Products, L.P., Titusville, NJ 08560) was applied to the lateral thorax of the dog. The initial side for patch placement was determined by a coin toss. Subsequent placements were made on alternate sides. The area for patch placement was carefully clipped free of hair without abrading the skin. The clipped area was brushed clean, but not scrubbed. The patch was placed on the clipped area, held in place for one minute to ensure adhesion and then covered with elastic tape (Elastikon, Johnson and Johnson, Arlington, TX 76004). The elastic tape was covered with a single layer of bandaging tape (Vetwrap, 3M, St. Paul, MN 55144). The patches remained in place until the end of each trial. 


\subsection{Anesthesia and Instrumentation}

All dogs had food, but not water withheld for 12 hours prior to the induction of anesthesia. The induction of anesthesia occurred at the same time each day for each dog to avoid any influence of MAC alterations associated with circadian patterns. Anesthesia was induced by facemask with isoflurane (Isoflo, Abbott Laboratories, North Chicago, IL 60064 ) in 100 percent oxygen. Following induction, the trachea was intubated with an appropriately sized endotracheal tube and the dogs were connected to a rebreathing circle system with a fresh gas flow of $30 \mathrm{ml} / \mathrm{kg} / \mathrm{min}$. The dogs were immediately placed on intermittent positive pressure ventilation (SurgiVet ParaPAC ventilator, SurgiVet Inc., Waukesha, WI 53186), with rate and tidal volume adjusted to maintain normocapnea (ET $\mathrm{CO} 2_{2}$ of $32-42 \mathrm{mmHg}$ ). Initial isoflurane vaporizer settings were $1.5-2 \%$.

Immediately following the induction of anesthesia, a 20 gauge, $3.2 \mathrm{~cm}$ catheter (Abbocath -T, Abbott Ireland, Sligo, Republic of Ireland) was placed in a cephalic vein for the administration of a balanced electrolyte solution (Normosol-R, Abbott Laboratories, North Chicago, IL 60064) at $5 \mathrm{ml} / \mathrm{kg} / \mathrm{hr}$ for the duration of anesthesia. An 18 gauge, $28 \mathrm{~cm}$ through the needle catheter (Venocath - 16, Abbott Ireland, Sligo, Republic of Ireland) was placed in the jugular vein for obtaining venous samples for fentanyl analysis. The jugular catheters were placed only when dogs were receiving fentanyl transdermally. The catheter was placed in the jugular vein opposite the side on which the patch was located. A 22 gauge, $3.2 \mathrm{~cm}$ catheter was placed in the dorsal pedal artery. A pressure transducer was connected to the catheter with non-compliant tubing for direct arterial pressure measurement. A multi-function monitor (Biochem International 9100 Multigas Monitor, BCI, Waukesha, WI 53188) was used. The arterial catheter was also used to obtain samples for blood gas and acid-base analysis. Inspired and end-tidal inhalant concentration $\left(\mathrm{ET}_{\mathrm{INHAL}}\right)$ and the partial pressure of $\mathrm{CO}_{2}$ in the expired gas $\left(\mathrm{ET}_{\mathrm{CO} 2}\right)$ were measured with a 
sidestream analyzer (Biochem International 9100 Multigas Monitor, BCI, Waukesha, WI 53188). External calibration of the monitor and verification of isoflurane and carbon dioxide determinations was performed prior to and after each trial (Anesthesia Calibration Gas, Criticare Systems Inc., Waukesha, WI 53186). A standard lead II ECG, esophageal temperature and oxygen saturation $\left(\mathrm{S}_{\mathrm{p}} \mathrm{O}_{2}\right)$ (Biochem International 9100 Multigas Monitor, BCI, Waukesha, WI 53188) were monitored during anesthesia.

\subsection{Data Collection}

Heart rate $(\mathrm{HR})$, respiratory rate $(\mathrm{RR})$, and rectal temperature were recorded immediately prior to the induction of anesthesia. The HR, RR, esophageal temperature (TEMP), $\mathrm{ET}_{\mathrm{CO} 2}, \mathrm{~S}_{\mathrm{P}} \mathrm{O}_{2}, \mathrm{ET}_{\mathrm{INHAL}}$, systolic blood pressure (SBP), diastolic blood pressure (DBP), and mean blood pressure (MBP) were recorded at 15 minutes and 30 minutes following induction, and prior to the application of each electrical stimulation. The HR, $\mathrm{RR}$, and rectal temperature were also recorded at 15,30 and 90 minutes following the end of the anesthetic period.

Samples for arterial blood gas and acid base analysis $\left(\mathrm{pH}, \mathrm{P}_{\mathrm{a}} \mathrm{O}_{2}, \mathrm{P}_{\mathrm{a}} \mathrm{CO}_{2}, \mathrm{HCO}_{3}, \mathrm{ABE}\right)$ were drawn immediately prior to application of the first electrical stimulus, and following the last application of electrical stimulus. Samples were drawn into $1 \mathrm{ml}$ heparinized plastic syringes and analyzed immediately (IRMA Series 2000 Blood Analysis System, Diametrics Medical Inc., St. Paul, MN 55113). The values obtained with the IRMA were compared with results from the clinical pathology laboratory at Louisiana State University and the results were consistently similar. Internal self calibration of the blood gas analysis system was carried out prior to each sample analysis.

\subsection{Body Temperature}

During the C-NORM and F-NORM treatments, the dogs were kept warm with thermostatically controlled circulating hot water blankets and covered with towels. The 
dogs were maintained at a TEMP within $1^{\circ} \mathrm{C}$ of the baseline TEMP recorded prior to the induction of anesthesia.

During the C-HYPO and F-HYPO treatments, immediately after induction, the dogs were actively cooled to a TEMP of 34 to $35^{\circ} \mathrm{C}$ by placing towel wrapped ice packs in the inguinal and axillary regions. The target temperature for the HYPO treatment was chosen because it reflected the degree of hypothermia expected in animals during routine anesthesia and surgery that do not receive aggressive heat supplementation. Target temperatures for all treatments were held constant for one hour prior to the beginning of the first MAC determination.

Animal were placed in lateral recumbency with the sham or fentanyl patch on the dependent side. Care was taken to ensure that the patches did not come in contact with the circulating water blankets or ice packs. There was no attempt to rewarm hypothermic animals in the post anesthetic period.

\subsection{Determination of Minimum Alveolar Concentration}

Two 22 gauge needle electrodes connected to an electrical stimulator (Grass S88 Stimulator, Astro-med Inc., West Warwick, RI 02893) were inserted $4 \mathrm{~cm}$ apart in the buccal mucosa of the lower jaw. Electrical stimulation was delivered at 50 cycles per second, 6.5 milliseconds duration, at 40 volts (Eger et al. 1965, Valverde et al. 2003). Stimulator output was verified with a voltmeter prior to each trial.

During MAC determinations, a positive response was defined as gross purposeful movement of the head, trunk, or extremities. Licking, chewing, and swallowing were not considered purposeful (Eger et al. 1965). If no movement occurred after stimulation, the inhalant concentration was decreased by 20 percent and held constant for 15 minutes to allow for inhalant equilibration. The stimulation was then repeated. This process continued until a movement was elicited. Once movement was elicited, the inhalant concentration was 
increased by 10 percent and held constant for 15 minutes to allow for inhalant equilibration. Stimulation was repeated. The MAC was considered be the inhalant concentration midway between the highest concentration at which movement was elicited and the lowest concentration at which no movement occurred. The differences between the mean MAC values for the normothermic dogs with and without TDF were calculated by adding the MAC values for each dog in each group and determining the mean. The mean percentage difference between the normothermic group without fentanyl and with fentanyl was then determined by averaging the difference between the MAC values for each dog in each group.

\subsection{Fentanyl Concentration Determination}

Venous blood samples for determination of fentanyl concentrations were drawn prior to patch application, prior to the induction of anesthesia, and 15 minutes post anesthesia. For F-NORM and F-HYPO treatments $3 \mathrm{ml}$ samples were drawn from the jugular catheter immediately prior to each application of electrical stimuli and at 30 and 90 minutes after discontinuing anesthesia. For C-NORM and C-HYPO treatments, samples were drawn prior to the induction of anesthesia and at 30 minutes after discontinuing anesthesia to confirm the absence of any fentanyl in these treatments. Each blood sample was placed in a serum tube, cooled and then centrifuged to harvest the serum. The serum was stored at $70^{\circ} \mathrm{C}$ until the fentanyl concentration determination was performed.

Fentanyl concentration determination was performed by radioimmunoassay (Coat-ACount $^{\circledR}$ Fentanyl, Diagnostic Products Corporation, Los Angeles CA 90045). Measurement of serum fentanyl concentrations using a radioimmunoassay (RIA) has previously been found to result in overestimation of the serum concentrations by up 29-94\% (Schüttler and White, 1984). Overestimation was related to a reduction in binding sites for the labeled fentanyl after pre-incubation of the sample and antiserum. To overcome this problem the 
following steps were followed: 1) the antiserum was added to the sample and labeled drug as the final step; 2) calibration curves were performed using the pooled dogs blank serum, and finally; 3) each step of the RIA was carried out identically to reduce variability (Schüttler and White, 1984). Once these steps are instituted the comparison of a fentanyl RIA with gas-liquid chromatography (GLC) demonstrated the validity of the RIA as an accurate measurement technique for fentanyl concentrations. Spiked samples were compared at different fentanyl concentrations and no statistically significant differences in the mean values measured by GLC and the RIA were noted (Woestenborghs et al, 1987). Gas-liquid chromatography is taken to be the gold standard for evaluating serum concentrations of drugs.

In this study calibration curves were obtained by obtaining a pool of negative serum from the dogs, then spiking the samples with known amounts of fentanyl. The assay was then performed on these samples and results plotted and compared with the standard curve for the Coat-A-Count fentanyl assay with adjustments made for variation. The interassay coefficients of variation over the range of concentrations of $0.25,0.5,1.0,2.5$, and 4.0 $\mathrm{ng} / \mathrm{ml}^{-1}$ was $5.7,9.8,2.3,5.2$, and $8.8 \%$ respectively $(\mathrm{n}=20)$. The intra assay coefficients of variation for these same concentrations were 5.4, 9.5, 2.3, 5.4, and $9.3 \%$, respectively. Values less than $10 \%$ are considered acceptable for both intra and interassay coefficients of variation (Schuttler et al, 1984). The RIA is very specific for fentanyl and has no cross reactions with metabolites of fentanyl. All samples in this study were assayed in duplicate. The limit of detection of this assay was $0.08 \mathrm{ng} / \mathrm{ml}^{-1}$ but the proven level of quantification for the assay was $0.10 \mathrm{ng} / \mathrm{ml}^{-1}$. The fentanyl RIA has been used in numerous fentanyl studies in animals (Kyles et al, 1996; Wilkinson et al, 2001; Foley et al, 2001; Carroll et al, 1999; Egger et al, 2003; Pettifer and Hosgood, 2003; Pettifer and Hosgood, 2004). 


\subsection{Statistical Analysis}

- Sample Size Assessment

With a complete randomized block design, (blocked by dog), the intra-dog variation is estimated to be small (SD $\sim 10 \%$ ). The effect of inter-dog variation is minimized by the design and the analysis such that all dogs receive all treatments. With an expected difference of at least $50 \%$ of MAC between the treated and untreated control and the most severe treatment protocol (hypothermia and fentanyl), using a sample size of $n=6$ and setting $\alpha$ at 0.05 , the power was $100 \%$, implying certainty that this magnitude of difference would be detected. The minimal difference in MAC values between treatments detected with these criteria with at least $80 \%$ power was approximately $20 \%$. Had the difference between the treatments been as low as $10 \%$, the power of the investigation would have been reduced to $50 \%$, thus there would have been only a $50 \%$ likelihood that this difference (if real) would have been detected. By increasing $\alpha$ to 0.1 , the power could be increased to $100 \%$. The investigators believed that the consequence of increasing alpha to 0.1 , and thus increasing the risk of concluding a difference when there is not one, would not seriously impact animals' health and hence obviates unnecessarily increasing sample size (the sample size would have to have been increased to 13 for $90 \%$ power and to 28 for $100 \%$ power).

- Statistical Analysis

All results are expressed as mean \pm SEM, and differences were considered significant when $p \leq 0.05$. PROC UNIVARIATE, PROC MIXED, and PROC GLM (SAS v9.0, SAS Institute, Cary, NC) was used for the analysis.

The MAC was evaluated for normality using the Shapiro-Wilk statistic with the null hypothesis of normality rejected at $\mathrm{p} \leq 0.05$. Effect of protocol on MAC was assessed using a mixed effect linear model that included the fixed effect of protocol (4 levels) and the random variance of each dog. The repeated protocols on each dog were also accounted for 
in the model. If a significant effect of protocol on MAC at $p \leq 0.05$ was determined then comparisons between protocols were made using least means squares with a Scheffe adjustment to maintain $\alpha$ at 0.05 .

For the purpose of describing the four protocols, comparisons were made between protocols for heart rate, mean arterial blood pressure, and body temperature at the time of MAC determination. These variables were considered continuous and were normally distributed with failure to reject the null hypothesis of normality at $\mathrm{p} \leq 0.05$ using the Shapiro-Wilk statistic. A repeated measures ANOVA was used to evaluate the hear rate, mean arterial blood pressure, and temperature. Where significant effect of treatment at $\mathrm{p} \leq$ 0.05 was found, comparisons were made with the Scheffe adjustment to maintain alpha at 0.05 .

The PAUC was compared for C-FENT and H-FENT. The PAUC was considered to be continuous and normally distributed with failure to reject the null hypothesis of normality at $\mathrm{p} \leq 0.05$ using the Shapiro-Wilk statistic. A paired t-test was used with significance determined at $\mathrm{p} \leq 0.05$. 
CHAPTER 4. RESULTS AND DISCUSSION 


\subsection{Results}

The mean $( \pm$ SEM) MAC for the C-NORM treatment $(1.20 \pm 0.17 \%)$ was significantly higher $(p<0.05)$ than the MAC for the C-HYPO treatment $(0.89 \pm 0.18 \%)$, the F-NORM treatment $(0.76 \pm 0.10 \%)$, and the F-HYPO treatment $(0.81 \pm 0.17 \%)$. ( Figure 3$)$ There was no significant difference between the MAC values for the C- HYPO, F-NORM, and F-HYPO treatments. The mean reduction in isoflurane in F-NORM compared to CNORM was $36.6 \% \pm 0.47 \%$.

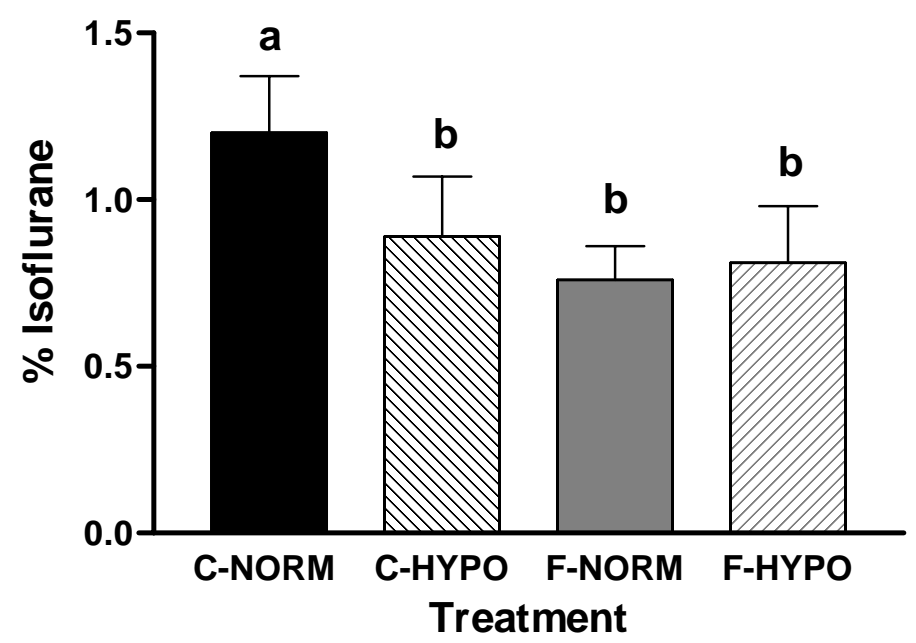

Figure 6. Mean ( \pm SEM) Minimum Alveolar Concentration (\%) for isoflurane CNORM (control normothermia), C-HYPO (control hypothermia), F-NORM (fentanyl normothermia), and F-HYPO (fentanyl hypothermia). Means with different superscripts are significantly different $(\mathrm{p} \leq 0.05)$

Heart rate and mean arterial blood pressure determined at the time of MAC determination were not significantly different between treatments. The mean TEMP in normothermic dogs $\left(37.45 \pm 0.06^{\circ} \mathrm{C}\right)$ was significantly lower than that of hypothermic $\operatorname{dogs}$ $\left(34.45 \pm 0.09^{\circ} \mathrm{C}\right)$

There was no detectable fentanyl in control dogs. The mean fentanyl PAUC for FNORM $(60.05 \pm 13.03 \mathrm{ng} / \mathrm{ml} / \mathrm{hr})$ and F-HYPO $(41.88 \pm 14.28 \mathrm{ng} / \mathrm{ml} / \mathrm{hr})$ were not significantly different. 


\subsection{Discussion}

Normothermic dogs receiving transdermal fentanyl had a mean reduction in isoflurane MAC of $36.6 \%$ compared to normothermic dogs without transdermal fentanyl. In a similar study in cats, there was a significant reduction in MAC of between $17.8 \%$ and $18.1 \%$ depending on the size of the patch applied ( 25 or $50 \mathrm{mcg} / \mathrm{hr})$ compared to normothermic cats without transdermal fentanyl (Yackey et al. 2004). A $65 \%$ reduction in the MAC of enflurane anesthetized dogs receiving intravenous fentanyl has been reported (Murphy and Hug, 1982). In these dogs high serum fentanyl concentrations of 25-30 ng/ml were recorded (Murphy and Hug, 1982). In our study, serum fentanyl concentrations were on average, below $2 \mathrm{ng} / \mathrm{ml}$, possibly accounting for the smaller reduction in MAC.

Different inhaled anesthetics have different effects on cardiovascular function, specifically dermal perfusion, which could alter the serum concentrations of fentanyl during transdermal administration. An investigation of serum fentanyl concentrations in dogs receiving transdermal fentanyl and anesthetized with either halothane or isoflurane described an effect of inhalant on the magnitude of reduction (Pettifer and Hosgood, 2004).

In the present investigation, the MAC reduction in hypothermic isoflurane anesthetized dogs was consistent with previous work that demonstrated a decrease of 2-6\% in isoflurane MAC for every $1^{\circ} \mathrm{C}$ decrease in temperature in dogs (Quasha et al. 1980). The MAC reduction produced by hypothermia during anesthesia with different inhalants is not uniform. For a $10{ }^{\circ} \mathrm{C}$ decrease in temperature there is a $50 \%$ decrease in MAC for halothane whereas cyclopropane MAC decreases only $25 \%$. The less oil soluble inhalants demonstrate smaller reductions in MAC, while the more lipid soluble inhaled anesthetics have greater reductions (Quasha et al, 1980). The gas phase potency of inhaled anesthetics increase with decreasing temperature. There is an associated increase in anesthetic solubility with a decrease in temperature so that the aqueous phase potencies remain relatively 
constant, but this will vary depending on the solubility of the inhalant (Franks and Lieb, 1996). In the current investigation hypothermic animals demonstrated a $3^{\circ} \mathrm{C}$ temperature decrease, suggesting a maximum decrease in MAC of up to $18 \%$. The difference between $18 \%$ and the observed $25 \%$ amounts to a very small difference in vaporizer setting $(0.084$ $\%)$ and is of little clinical relevance.

The difference in MAC reduction between the normothermic and hypothermic TDF groups and the hypothermic sham patched group were not statistically significant. This observation implies that no additional sparing effect or analgesia was provided by the transdermal fentanyl in hypothermic animals. If the transdermal fentanyl were providing analgesia in the hypothermic group a greater reduction in MAC would be expected. The lack of anesthetic sparing effect of transdermally administered fentanyl in this investigation could be the result of a significant reduction in uptake of fentanyl from the dermal depots during hypothermia.

The AUC was evaluated for each of the fentanyl groups, but due to variations in the time taken to complete each MAC study, we also evaluated the PAUC for the one hour period immediately preceding the final MAC determination to standardize the time included in the AUC assessment of fentanyl concentration. It was decided that this would be more reflective of the actual fentanyl concentrations responsible for the MAC determination compared to evaluating the area under the curve for the entire duration of the study which was variable from animal to animal and treatment to treatment. The AUC and PAUC were not significantly different between F-HYPO and F-NORM. Considerable inter- and intraindividual variations in serum fentanyl concentrations achieved during transdermal administration may have obscured any chance of detecting a real difference. As an example, one dog in the hypothermia group had detectable serum fentanyl concentrations prior to induction of anesthesia but had undetectable levels for the duration of the study. Serum 
fentanyl concentrations returned to pre-anesthesia levels in this animal at the conclusion of the MAC determination study. Such marked variability in serum fentanyl concentrations decreases the likelihood of detecting any real difference between treatment groups. Given the variability in PAUC observed in the current investigation, a sample size of 20 would be required to determine a difference with $80 \%$ power. When determining the sample size for this study we did not include the PAUC in our considerations but rather focused on the sample size needed to identify differences in the MAC values. Because of the extreme variability in the study a $p$ value $\leq 0.05$ resulted in $18 \%$ power with the sample size of 6 . With sample size unchanged and $\mathrm{p} \leq 0.2$ power would increase to $44 \%$ but still remain below an acceptable level. Thus increasing sample size is likely to have the most impact on better defining this result.

A possible explanation for lack of a detectable difference in effect (MAC) between hypothermic dogs receiving transdermally administered fentanyl and those not is that a shift out of the biophase for fentanyl may have occurred. In this case changes in PAUC may not have been noted but there would be a decreased efficacy of the fentanyl.

A three compartment model is used to describe distribution of fentanyl in the body. The three compartments are the plasma in the extracellular space, the interstitial fluid in the extracellular space and the cellular space (Bentley et al, 1982; McClain and Hug, 1980; Fung and Eisele, 1980; Schleimer et al, 1978). Under normal body conditions approximately 10 $\%$ of the fentanyl dose is present in the extracellular fluid including the vascular space and approximately $90 \%$ is present intracellularly (Bailey et al, 2000). Equilibrium between ionized fentanyl, the free base, and the fentanyl molecules bound to macromolecules exists (Bailey et al, 2000). The concentration of ionized fentanyl in the interstitial fluid (or biophase) determines the pharmacologic effect, because the opioid receptors are located at the cell surface. A small decrease in extracellular $\mathrm{pH}$ shifts the equilibrium toward higher 
ionized fentanyl and results in more base fentanyl being released from the cell in an attempt to re-establish the equilibrium. The resulting change in equilibrium and increase in ionized fentanyl in the interstitial fluid results in enhancement of pharmacologic effect (Bailey et al, 2000). This would initially result in no alteration in serum fentanyl concentration as the shift is from the intracellular base fentanyl to the ionized fentanyl. Eventually a decrease in serum concentrations would be noted as equilibrium was re-established. In this study no decrease in plasma levels were noted nor was there any increase in the reduction of MAC compared to hypothermic dogs with no transdermal fentanyl.

In summary, the use of transdermal fentanyl in normothermic dogs did result in a significant reduction in the MAC for isoflurane. Transdermal fentanyl did not alter the MAC for isoflurane in hypothermic dogs. Further investigation of the PAUC with an appropriate sample size would be needed to fully evaluate the impact of hypothermia on intra-anesthesia fentanyl concentrations.

It is recommended that animals with transdermal fentanyl patches in place should be maintained within a normothermic temperature range in order for transdermal fentanyl to be effective. 
REFERENCES 
Allescher, H.D., Ahmad, S., et al. (1988). "Inhibitory opioid receptors in canine pylorus”. American Journal of Physiology 255:G352-360

Atcheson, R. and Lambert, D.G. (1994). "Update on opioid receptors”. British Journal of Anaesthesia 73:32-134.

Bailey, P.L., Egan, T.D., et al. (2000). “Intravenous Opioid Anesthesia”. From Anesthesia, $5^{\text {th }}$ edition, ed. Miller, RD Churchill Livingstone, Philadelphia, PA p273-376

Bayguinov, O., Sanders, K.M. (1993). "Regulation of neural responses in the canine pyloric sphincter by opioids”. British Journal of Pharmacology 108(4):10241030

Becker, L.D., Paulson, B.A., et al. (1976). "Biphasic respiratory depression after fentanyldroperidol or fentanyl alone used to supplement nitrous oxide anesthesia”. Anesthesiology 44:291-296

Bentley, J.B., Borel, J.D., et al. (1982). “Age and Fentanyl Pharmacokinetics”. Anesthesia and Analgesia 61:968-972

Bowdle, T.A. (1987). "Butorphanol improves $\mathrm{CO}_{2}$ response and ventilation after fentanyl anesthesia”. Anesthesia and Analgesia 66:517-522

Bronson, J.B., Weinger, B., et al. (1989). "Opiate induced muscle rigidity is mediated by mu, and not delta or kappa receptors in the rat”. Anesthesiology 71:A599.

Broome, I.J., Wright, B.M., et al. (1995). "Postoperative analgesia with transdermal fentanyl following lower abdominal surgery”. Anaesthesia 50:300-303.

Brooks, P.M., Day, R.O., (1991). "Nonsteroidal anti-inflammatory drugs-differences and similarities". New England Journal of Medicine 324:176-725

Brown, D.L., Carpenter, R.L., Thompson, G.E. (1990). Comparison of 0.5\% ropivicaine and $0.5 \%$ bupivicaine for epidural anesthesia in patients undergoing lower extremity surgery”. Anesthesiology 72:633-636

Butterworth, J.F., Strichartz, G.R., (1990). "Molecular mechanisms of local anesthesia: a review”. Anesthesiology 72:722-734

Bylund, D.B., Eikenburg, D.C., et al. (1993). "International union of pharmacology nomenclature of adrenoreceptors”. Pharmacology Review 46:121

Cabot, P.J., Cramond, T., et al. (1996). "Quantitative autoradiography of peripheral opioid binding sites in rat lung”. European Journal of Pharmacology 310(1):47-53.

Cahalan, M.K., Lurz, F.W., et al. (1987). "Narcotics decrease heart rate during inhalational anesthesia”. Anesthesia Analgesia 66:166-170. 
Carlsson, C., Smith, D.S., et al. (1982). "The effects of high dose fentanyl on cerebral circulation and metabolism in rats”. Anesthesia 57(5):375-380.

Carroll, G.L., Hooper, R.N., et al. (1999). "Pharmacokinetics of fentanyl after intravenous and transdermal administration in goats". American Journal of Veterinary Research 60:986-991.

Carsten, E., Yokota, T., et al. (1979). "Inhibition of spinal neuronal responses to noxious skin heating by stimulation of mesencephalic periaqueductal gray in the cat”. Journal of Neurophysiology 42:558-568

Clive, D.M., Stoff, J.S., (1984). "Renal syndromes associated with nonsteroidal antiinflammatory drugs”. New England Journal of Medicine 310:563-572

Coggeshall, R.E., Chung, K., et al. (1996). "Primary afferent axons in the tract of lissauer in the monkey”. Journal of Comparative Neurology 27:423-426.

Contet, C., Matifas, A., et al. (2004). "No evidence for G-protein-coupled epsilon receptor in the brain of triple opioid receptor knockout mouse”. European Journal of Pharmacology 492(2-3):131-136

Correa-Sales, C., Rabin, B.C., et al. (1992). “A hypnotic response to dexmedetomidine, an alpha 2 agonist, is mediated in the locus ceruleus in rats”. Anesthesiology 76:948

Cousins, M.J. and Mather L.E. (1984). "Intrathecal and epidural administration of opioids”. Anesthesiology 61:276-310

Dahl, J.B. and Kehlet, H. (1991). "Non-steroidal anti-inflammatory drugs: rationale for use in severe postoperative pain”. British Journal of Anaesthesia 66:703712

de Leon-Cassasola, O.A., Lema, M.J. (1996). "Post-operative epidural opioid analgesia: what are the choices?” Anesthesia and Analgesia 83:867-875

Dennis, S.G. and Melzack, R. (1977). "Pain signalling systems in the dorsal and ventral spinal cord”. Pain 4(2):97-132.

Donner, B., Zenz, M., et al. (1996). "Direct conversion from oral morphine to transdermal fentanyl: a multicenter study in patients with cancer”. Pain 64:527-534

Dowd, G., Gaynor, J.S., et al. (1997). “A comparison of transdermal fentanyl and oral phenylbutazone for postoperative analgesia in sheep” (abstr), In: Proceedings. Annual Meeting of American College of Veterinary Anesthesiologists 13.

Duragesic product monograph. Jansenn Pharmaceutica products, LP. Titusville, NJ 
Dyson, D.H., Doherty, T., et al. (1990). "Reversal of Oxymorphone sedation by Naloxone, Nalmefene, and Butorphanol”. Veterinary Surgery 19(5):398-403

Egger, C.M., Duke, T., et al. (1998). “Comparison of plasma fentanyl concentrations by using three transdermal fentanyl patch sizes in dogs". Veterinary Surgery 27:159-166

Egger, C.M., Glerum, L.E., et al. (2003). "Plasma fentanyl concentrations in awake cats and cats undergoing anesthesia and ovariohysterectomy using transdermal administration”. Veterinary Anesthesia and Analgesia 30:229-236

Eger, E.I., Saidman, L.J., et al. (1965) "Minimum alveolar concentration: a standard of anesthetic potency”. Anesthesiology 26:756-763.

Feld, L.H., Champeau, L.W., et al. (1989). "Preanesthetic medication in children: a comparison of oral transmucosal fentanyl citrate versus placebo". Anesthesiology 71:374-377

Feldman, H.S., Covino, B.G., (1988). "Comparative motor-blocking effects of bupivicaine and ropivicaine, a new amino amide local anesthetic inn the rat and dog”. Anesthesia and Analgesia 67:1047-052

Foley, P.L., Henderson, A.L., et al. (2001). "Evaluation of fentanyl transdermal patches in rabbits. Blood concentrations and physiologic response”. Comparative Medicine 51:239-244.

Franks, J.N., Boothe, H.W., et al. (2000). "Evaluation of transdermal fentanyl patches for analgesia in cats undergoing onychectomy”. Journal of the American Veterinary Medical Association 7:1013-1020.

Franks, N.P. and Lieb, W.R. (1996). "Temperature dependence of the potency of volatile general anesthetics”. Anesthesiology 84:716-719

Freye, E. and Kuschinsky, K. (1976). "Effects of fentanyl and droperidol on the dopamine metabolism of the rat striatum". Pharmacology 14(1):1-7.

Fung, D.L. and Eisele, J.H. (1980). "Fentanyl Pharmacokinetics in awake volunteers”. Journal of Clinical Pharmacology 20:652-657

Gilberto, D.B., Motzel, S.I., et al. (2003). "Postoperative pain management using fentanyl patches in dogs”. Contemporary topics 42(4):21-26

Glass, P.S.A., Jhaveri, R.M., et al. (1994). "Comparison of potency and duration of action of nalmefene and nalaxone”. Anesthesia and Analgesia 78:536-541.

Glerum, L.E., Egger, C.M., et al. (2001). “Analgesic effect of the transdermal fentanyl patch during and after feline ovariohysterectomy”. Veterinary Surgery 30: 351-358. 
Gloor, P., Vera, C.L., et al. (1961). "Investigations on the mechanism of epileptic discharges in the hippocampus”. Epilepsia 2:42-62.

Gourlay, G.K., Kowalski, S.L., et al. (1989). “The transdermal administration of fentanyl in the treatment of post-operative pain: pharmacokinetics and pharmacodynamic effects”. Pain 37:193-202

Griesel, J.E., Mogil, J.S. (2000). “Effects of supraspinal orphanin FQ/nociceptin”. Peptides 21:1037-1040

Grond, S., Radbruch, L., et al. (2000). “Clinical pharmacokinetics of transdermal opioids, focus on transdermal fentanyl”. Clinical Pharmacokinetics 38(1):5989.

Guyton, A.C. and Hall, J.E. (1996). “Somatic Sensations”. In: Textbook of Medical Physiology. $9^{\text {th }}$ ed. Philadelphia, PA, W.B. Sauders:611.

Harvey-Clark, C.J., Gillespie, K., et al. (2000). “Transdermal Fentanyl compared with parenteral buprenorphine in post-surgical pain in swine”. A case study. Laboratory Animals 34:386-398.

Holley, F.O. and van Steennis, C. (1988). "Postoperative analgesia with fentanyl: pharmacokinetics and pharmacodynamics of constant rate i.v. and transdermal delivery”. British Journal of Anaesthesia 60:608-613.

Houghton, A.K., Hewitt, E., et al. (1997). "Enhanced withdrawal responses to mechanical and thermal stimuli after bone injury". Pain 73:325-337

Hudspith, M.J. (1997). "Glutamate: a role in normal brain function, anesthesia, analgesia and CNS injury”. British Journal of Anaesthesia 78:731-747.

Hug, C.C. and Murphy, M.R. (1981). "Tissue redistribution of fentanyl and termination of its effects in rats". Anesthesiology 55:369-375

Imrie, M.M., Hall, G.M. (1990). "Body temperature and anaesthesia”. British Journal of Anaesthesia 64:346-354

Jones, J.G., Sapsford, D.J., et al. (1990). “Postoperative hypoxemia: Mechanisms and time course”. Anaesthesia 45:566-573.

Kamenetsky, S., Rabinowitz, R., et al. (1997). "Neuroanatomical aspects of mydriatic action of morphine in rats". Journal of Ocular Therapeutics 13(5): 405-413.

Kieffer, B.L. (1995). "Recent advances in molecular recognition and signal transduction of active peptides: Receptors for opioid peptides”. Cell Molecular Neurobiology 15:615-620

Kemmotsu, O., Hashimoto, Y., et al. (1973). "Inotropic effects of isoflurane on mechanics of contraction in isolated cat papillary muscles from normal and failing hearts”. Anesthesiology 39:470-477. 
Kety, S.S. and Schmidt, C.F. (1945). "The determination of cerebral blood flow in man by the use of nitrous oxide in low concentrations”. American Journal of Physiology 53:1443-1447.

Kronenberg, R.H., (2002). "Ketamine as an analgesic: parenteral, oral, rectal, subcutaneous, transdermal, and intranasal administration”. Journal of Pain and Palliative Care Pharmacotherapy 16(3):27-35

Kurz, A., Plattner, O., et al. (1993). "The threshold for thermoregulatory vasoconstriction during nitrous oxide/isoflurane anesthesia is lower in elderly than in young patients”. Anesthesiology 79(3):465-469.

Kyles, A.E., Hardie, E.M., et al. (1998). “Comparison of transdermal fentanyl and intramuscular oxymorphone on postoperative behaviour after ovariohysterectomy in dogs”. Research in Veterinary Science 65:245-251.

Kyles, A.E. (1998). “Transdermal fentanyl”. The Compendium 20:721-726

Kyles, A.E., Papich, M., et al. (1996). “Disposition of transdermally administered fentanyl in dogs”. American Journal of Veterinary Research 57(5):715-719.

Lakhlani, P.P., MacMillan, L.B., et al. (1997). Substitution of a mutant alpha2aadrenergic receptor via "hit and run"gene targeting reveals the role of this subtype in sedative, analgesic, and anesthetic sparing responses in vivo". Proceedings of the National Academy of Science USA 94:9950

Lamont, L.A., Tranquilli, W.J., et al. (2000). "Physiology of Pain”. In: Mathews KA, ed. The Veterinary Clinics of North America. Philadelphia PA, W.B. Sauders 30(4):703-728.

Laster, M.J., Liu, J., et al. (1993). "Electrical stimulation as a substitute for the tail clamp in the determination of minimum alveolar concentration". Anesthesia and Analgesia 76:1310-1312.

Lee, D.D., Papich, M., et al. (2000). “Comparison of pharmacokinetics of fentanyl after intravenous and transdermal administration in cats". American Journal of Veterinary Research 61:672-677.

Lemke, K.A., Tranquilli, W.J., et al. (1996). “Ability of flumazenil, butorphanol, and Naloxone to reverse the anesthetic effects of oxymorphone-diazepam in dogs". Journal of the American Veterinary Medical Association 209(4):776-779

Liu, W.H. and Luxton, M.C. (1991). "The effect of prophylactic fentanyl on shivering in elective caesarean section under epidural analgesia”. Anaesthesia 46(5):344-348.

Lodge, D. and Anis, N.A. (1982). Effects of phencyclidine on excitatory amino acid activation of spinal interneurons in the cat”. European Journal of Pharmacology 77:203 
Longnecker, D.E. (1984). “Effects of General Anesthetics on the Microcirculation”. Microcirculation, Endothelium, and Lymphatics 1:129-184.

Macaluso, A.D., Connelly, A.M., et al. (1996). Oral transmucosal fentanyl citrate for premedication in adults”. Anesthesia and Analgesia 82:158-161

Mantyh, P.W. (1983). "Connections of midbrain Periaqueductal grey in the monkey. II. Descending efferent projections”. Journal of Neurophysiology 49(3):528594.

Marquardt, K.A, Tharratt, R.S., et al. (1995). "Fentanyl remaining in a transdermal system following three days of continuous use". Annals of Pharmacotherapy 29(10):969-971.

Martin, W.R., Eades, C.G., et al. (1976). “The effects of morphine and nalorphinelike drugs in the nondependent and morphine dependent chronic spinal dog”. Journal of Pharmacological Experimental Therapies197:517.

Marx, W., Shah, N., et al. (1989). "Sufentanil, alfentanil, and fentanyl: Impact on cerebrospinal fluid pressure in patients with brain tumors”. Journal of Neurosurgical Anesthesia 1:3-17.

Matthews, N.S., Peck, K.E., et al. (1997). “Transdermal fentanyl: absorption and plasma levels in horses” (abstr). In: Proceedings. $\underline{6}^{\text {th }}$ International Congress of Veterinary Anaesthesiologists 116.

McClain, D.A. and Hug, C.C. (1980). “Intravenous Fentanyl Kinetics”. Clinical Pharmacology Therapeutics 28:106-111

McCrackin, M.A., Harvey, R.C. (1992). "Butorphanol tartrate for partial reversal of opioid-induced respiratory depression and sedation with preservation of analgesia in the dog and cat”. Veterinary Surgery 21:83-87

Melzack, R. and Wall, .PD. (1965). "Pain mechanisms: a new theory”. Science 150:971-979.

Merskey, H. (1979). "Pain Terms: A list with definitions and notes on usage". International Association for the Study of Pain. Pain 6:249-261.

Meunier, J.C. (1997). "Nociceptin/orphanin FQ and the opioid receptor-like ORL 1 receptor”. European Journal of Pharmacology 340:1-15

Michiels, M. Hendricks, R., et al. (1977). “A Sensitive Radioimmunoassay for Fentanyl Plasma Levels in Dogs and Man”. European Journal of Clinical Pharmacology 12:153-158

Milde, L.N., Milde, J.H., et al. (1989). “Cerebral effects of fentanyl in dogs”. British Journal of Anaesthesia 63:710. 
Muir, W.W., Wiese, A.J., et al. (2003). "Effects of morphine, lidocaine, ketamine, and morphine-lidocaine-ketamine drug combination on minimum alveolar concentration in dogs anesthetized with isoflurane”. American Journal of Veterinary Research 64(9):1155-160

Murat, I., Levron, J.B., et al. (1988). "Effects of fentanyl on Baroreceptor reflex control of heart rate in newborn infants”. Anesthesiology 68:717-722

Murphy, M.R. and Hug, C.C. (1982). "The anesthetic potency of fentanyl in terms of its reduction of enflurane MAC”. Anesthesiology 57:485-488

Nage, I., Santha P., et al. (2004). "The role of the vanilloid (capsaicin) receptor (TRPV1) in physiology and pathology". European Journal of Pharmacology 500 (1-3):351-369

Nakajima, Y., Takamata, A., et al. (2004). "Effect of amino acid infusion on central thermoregulatory control in humans”. Anesthesiology 100:634-639.

Page, A.J., Brierley, S.M., et al. (2004). “The ion channel ASIC1 contributes to visceral but not cutaneous mechanoreceptor function”. Gastroenterology 127(6):1739-1747

Pathak, K.S., Brown, R.H., et al. (1984). "Effects of fentanyl and morphine on intraoperative somatosensory cortical-evoked potentials”. Anesthesia and Analgesia 63(9):833-837.

Pesonen, A., Leppaluoto, J. et al. (1990). “Mechanism of opioid induced atrial natriuretic peptide release in conscious rats”. Journal of Pharmacology and Experimental Therapies 254:690-693

Pettifer, G.R. and Hosgood, G. (2003). "The effect of rectal temperature on perianesthetic serum concentrations of transdermally administered fentanyl in cats anesthetized with isoflurane”. American Journal of Veterinary Research 64(12):1557-1561.

Pettifer, G.R. and Hosgood, G. (2004). "The effect of inhalant anesthetic and body temperature on peri-anesthetic serum concentrations of transdermally administered fentanyl in dogs”. Veterinary Anesthesia and Analgesia 31:109120

Pleuvry, B.J., (1991). “Opioid receptors and their ligands: natural and unnatural”. British Journal of Anaesthesia 66:370-380

Quasha, A.L., Eger, E.I., et al. (1980). “Determinations and applications of MAC”. Anesthesiology 53:315-334.

Rang, H.P., Bevan, S., et al. (1991). "Chemical activation of nociceptive peripheral neurons”. British Medical Bulletin 47:534-538 
Rawal, N., Mollefors, K., et al. (1983). “An experimental study of urodynamic effects of epidural morphine and naloxone reversal". Anesthesia and Analgesia 62:641-647

Reinscheid, R.K., Nothacker, H., et al. (2000). “The orphanin FQ/nociceptin gene: Structure, tissue distribution of expression and functional implications obtained from knockout mice”. Peptides 21:901-904

Robinson, T.M., Kruse-Elliott, K.T., et al. (1999). “A Comparison of Transdermal Fentanyl versus Epidural Morphine for Analgesia in Dogs Undergoing Major Orthopedic Surgery". Journal of the American Animal Hospital Association 35:95-100.

Roerig, D.L., Kotrly, K.J., et al. (1987). "First pass uptake of fentanyl, meperidine, and morphine in the human lung”. Anesthesiology 67:466-472.

Roscow, C.E., Moss, J. et al. (1982). "Histamine release during morphine and fentanyl anesthesia”. Anesthesiology 56:93-96

Roy, S.D. and Flynn, G.L. (1989). “Transdermal delivery of narcotic analgesics: comparative permeabilities of narcotic analgesics through cadaver skin". Pharmacology Research 6(10):825-32.

Safwat, A.M. and Daniel, D. (1983). “Grand mal seizure after fentanyl administration”. Anesthesiology 59(1):78.

Saidman, L.J. and Eger, E.I. (1964). "Effect of nitrous oxide and of narcotic premedication on the alveolar concentration of halothane required for anesthesia”. Anesthesiology 25:302-306.

Samra, S.K., Lilly, D.J., et al. (1984). "Fentanyl anesthesia and human brain-stem auditory evoked potentials”. Anesthesiology 61(3):261-265.

Scherk-Nixon M. (1996). "A study of the use of a transdermal fentanyl patch in cats”. Journal of the American Animal Hospital Association 32:19-24.

Schleimer, R., Benjamin, E., et al. (1978). "Pharmacokinetics of Fentanyl as Determined by Radioimmunoassay". Clinical Pharmacology Therapeutics 23:188-194

Schultheiss, P.J., Morse, B.C., et al. (1995). "Evaluation of a transdermal fentanyl system in the dog". Contemporary Topics in Laboratory Animal Science 34:75-81

Schüttler, J. and White, P.F. (1984). "Optimization of the Radioimmunoassays for Measuring Fentanyl and Alfentanil in Human Serum”. Anesthesiology 61:315-320

Sessler, D.I., Olofsson, C.I., et al. (1988) "The thermoregulatory thresholds in humans during nitrous oxide-fentanyl anesthesia”. Anesthesiology 69(3):357-364. 
Sessler, D.I. (1997). "Mild perioperative hypothermia”. New England Journal of Medicine 336:1630-1637.

Sessler, D., Moyayeri, A., et al. (1990). “Thermoregulatory vasoconstriction decreases cutaneous heat loss”. Anesthesiology 73:656-660.

Sessler, D. (2000). “Peri-operative heat balance”. Anesthesiology 92(2):578-596.

Sessler, D.I. (2000). “Temperature monitoring”. In: Miller, R.D. ed. Anesthesia Fifth ed. Philadelphia PA. Churchill Livingstone,1367-1389.

Singh,V.K., Bajpai, K., et al. (1997). "Molecular biology of opioid receptors: recent advances”. Neuroimmunomodulation 4(5-6):285-297.

Smith, A.A., Posner, L.P., et al. (2004). "Evaluation of the effects of premedication on gastroduodenoscopy in cats”. Journal of the American Veterinary Medical Association 225(4):540-544

Sonner, J.M. (2002). "Issues in the design and interpretation of minimum alveolar anesthetic concentration (MAC) studies”. Anesthesia and Analgesia 95:609614.

Souter, A.J., Fredman, B., et al. (1994). "Controversies in the perioperative use of nonsteroidal anti-inflammatory drugs”. Anesthesia and Analgesia 79:11781190

Sperry, R.J., Bailey, P.L., et al. (1992). "Fentanyl and sufentanil increase intracranial pressure in head trauma patients”. Anesthesiology 77(3):416-420.

Stanley, T.H., Hague, B., et al. (1989). Oral transmucosal fentanyl citrate (lollipop) premedication in human volunteers. Anesthesia and Analgesia 69:21-27

Stanski, D.R. (2000). "Monitoring depth of anesthesia”. In: Miller, R.D. ed. Anesthesia Fifth ed. Philadelphia, PA. Churchill Livingstone, 1087-1113.

Steffey, E.P., Baggot, J.D., Eisele, J.H. et al. (1994). “Morphine-isoflurane interactions in dogs, swine and rhesus monkeys. Journal of Veterinary Pharmacology and Therapeutics 17:202-210

Stein, C. (1995). “The control of pain in peripheral tissues by opioids”. New England Journal of Medicine 332:1685-1691

Stevens, W.C., Eger, E.I. $2^{\text {nd }}$ (1971). “Comparative evaluation of new inhalation anesthetics”. Anesthesiology 35(2):125-136.

Stoelting, R.K. (1987). “Opiod Agonists and Antagonists”. In: Pharmacology and Physiology in Anesthetic Practice. Philadelphia PA. J.B. Lippincott, 69-101. 
Stoelting, R.K. (1987). “Central Nervous System”. In: Pharmacology and Physiology in Anesthetic Practice. Philadelphia PA. J.B. Lippincott, 591-618.

Støen, R. and Sessler, D. (1990) "The thermoregulatory threshold is inversely proportional to isoflurane concentration”. Anesthesiology 72:822-827.

Stubhaug, A., Breivik, H., et al. (1997). "Mapping of punctuate hyperalgesia around a surgical incision demonstrates that ketamine is a powerful suppressor of central sensitization to pain following surgery”. Acta Anaesthesia

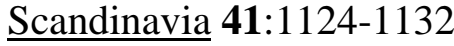

Takemori, A.e., Ikeda, M., et al. (1986). “The mu, kappa and delta properties of various opioid agonists”. European Journal of Pharmacology 123(3):357-361

Thompson, J.P., Bower, S., et al. (1998). "Perioperative pharmacokinetics of transdermal fentanyl in elderly and young adult patients”. British Journal of Anaesthesia 81:152-154.

Thompson, S.W.N., King, A.E., et al. (1990). “Activity dependant changes in rat ventral horn neurons in vitro; Summation of prolonged afferent evoked postsynaptic depolarization's produce a D-2-amino-5- phosphonovaleric acid sensitive windup”. European Journal of Neuroscience 2:638-643.

Thurmon, J.C., Tranquilli, W.J., et al. (1996). “Perioperative Pain and Distress”. In: Thurmon, J.C., Tranquilli, W, J., Benson, G.J., eds. Lumb and Jones' Veterinary Anesthesia. $3^{\text {rd }}$ ed. Baltimore MD. The Williams \& Wilkins Co, 45-46.

Trafton, J.A., Abbadie, C., et al. (2000). "Postsynaptic signalling via the mu opioid receptor: Responses of dorsal horn neurons to exogenous opioids and noxious stimulation”. Journal of Neuroscience 20:8578-8582

Vandam, L. (1980). “Drug therapy: Butorphanol”. New England Journal of Medicine 302:381-384

Valverde, A., Morey, T.E. et al. (2003). "Validation of several types of noxious stimuli for use in determining the minimum alveolar concentration for inhalation anesthetics in dogs and rabbits”. American Journal of Veterinary Research 64(8):957-961

Varvel, J.R., Shafer, S.L., et al. (1989). “Absorption characteristics of transdermally administered fentanyl”. Anesthesiology 70:928-934.

Washington, D., Sessler, D.I., et al. (1993). “Thermoregulatory responses to hyperthermia during isoflurane anesthesia in humans”. Journal of Applied Physiology 74(1):82-87.

Watcha, M.F., White, P.F. (1992). "Post-operative nausea and vomiting: Its etiology, treatment, and prevention”. Anesthesiology 77:162-165 
Weil, J.V., McCullough, R.E., et al. (1975). "Diminished ventilatory response to hypoxia and hypercapnia after morphine in normal man”. New England Journal of Medicine 292(21):1103-1106.

Wilkinson, A.C., Thomas, M.L., et al. (2001). "Evaluation of a Transdermal Fentanyl System in Yucatan Miniature Pigs”. Contemporary Topics 40(3):12-16

Willis, W.D. (1985). “Thalamocortical mechanisms of pain”. Advanced Pain Research 9:245-249.

Welch, J.A., Wohl, J.S., et al. (2002). "Evaluation of postoperative respiratory function by serial blood gas analysis in dogs treated with transdermal fentanyl”. Journal of Veterinary Emergency and Critical Care 12(2):81-87.

Woolf, C.J. and Wall, P.D. (1986). “The relative effectiveness of C-primary afferents of different origins in evoking a prolonged facilitation on the flexor reflex in the rat”. Journal of Neuroscience 6:1433-1450

Woolf, C.J. and Chong M-S. (1993). "Preemptive analgesia: Treating postoperative pain by preventing the establishment of central sensitization”. Anesthesia and Analgesia 77:362-379

Wright, J.C. (2002). "Evaluation of postoperative respiratory function by serial blood gas analysis in dogs treated with transdermal fentanyl”. Journal of Veterinary Emergency and Critical Care 12:81-87.

Woestenborghs, C.E., Stanski, D.R., et al. (1987). “Assay Methods for Fentanyl in Serum: Gas-Liquid Chromatography Versus Radioimmunoassay”. Anesthesiology 65:85-90

Wu, G, Whiteside G.T., et al. (2004). “A-37491, a selective P2X3/P2X(2/3) receptor antagonist, reverses inflammatory mechanical hyperalgesia through action at peripheral receptors in rats". European Journal of Pharmacology 504(12):45-53

Yackey, M., Ilkiw, J.E., et al. (2004). "Effect of transdermally administered fentanyl on the minimum alveolar concentration of isoflurane in cats". Veterinary Anesthesia and Analgesia 29:1-7.

Yaksh, T.L. and Hammond, D.L. (1982). "Peripheral and central substances involved in the rostrad transmission of nociceptive information”. Pain 13:1-86.

Yaksh, T.L. (1997). "Pharmacology and mechanisms of opioid analgesic activity". Acta Anaesthesiology Scandanavia 41:94-100

Yeo, W., Lam, K.K., et al. (1997). “Transdermal fentanyl for severe cancer-related pain”. Palliative Medicine 11(3):233-239

Zeltzer, L., Jay, S., et al. (1989). “The management of pain associated with pediatric procedures”. Pediatric Clinics of North America 36:941-964 
APPENDIX: RAW DATA 


\begin{tabular}{|c|c|c|c|c|c|c|c|c|c|}
\hline Dog & TX & Time & Fent & Temp & HR & RR & Systolic & Diastolic & Mean \\
\hline 9048 & 1 & 0 & 0 & 38.8 & 80 & 20 & & & \\
\hline 9048 & 1 & 15 & & 37.8 & 110 & 14 & & & \\
\hline 9048 & 1 & 30 & & 37.6 & 101 & 14 & 120 & 71 & 85 \\
\hline 9048 & 1 & MAC1 & & 37.2 & 97 & 14 & 115 & 63 & 76 \\
\hline 9048 & 1 & MAC2 & & 37.3 & 110 & 15 & 140 & 81 & 96 \\
\hline 9048 & 1 & MAC3 & & 37.2 & 87 & 14 & 127 & 69 & 86 \\
\hline 9048 & 1 & p15 & 0 & 38 & 80 & 16 & . & & . \\
\hline 9048 & 2 & 0 & 0 & 37.2 & 108 & 14 & & & \\
\hline 9048 & 2 & 15 & & 36.4 & 112 & 12 & & & \\
\hline 9048 & 2 & 30 & & 36 & 88 & 12 & 126 & 72 & 89 \\
\hline 9048 & 2 & MAC1 & & 34.1 & 85 & 11 & 104 & 59 & 74 \\
\hline 9048 & 2 & MAC2 & & 34.2 & 160 & 30 & 140 & 91 & 110 \\
\hline 9048 & 2 & MAC3 & & 34.5 & 140 & 26 & 122 & 71 & 90 \\
\hline 9048 & 2 & p15 & 0 & 36.2 & 100 & 10 & & & \\
\hline 9048 & 3 & 0 & 0.896 & 38 & 56 & 12 & & & \\
\hline 9048 & 3 & 15 & 0.601 & 37.2 & 85 & 10 & . & & \\
\hline 9048 & 3 & 30 & 0.584 & 36.8 & 81 & 10 & 96 & 51 & 66 \\
\hline 9048 & 3 & MAC1 & 1.569 & 36.9 & 84 & 10 & 82 & 43 & 54 \\
\hline 9048 & 3 & MAC2 & 1.341 & 37 & 80 & 10 & 92 & 50 & 64 \\
\hline 9048 & 3 & MAC3 & 1.412 & 37.1 & 68 & 10 & 99 & 48 & 65 \\
\hline 9048 & 3 & MAC4 & 1.287 & 37.2 & 61 & 10 & 99 & 46 & 63 \\
\hline 9048 & 3 & MAC5 & 1.677 & 37.3 & 56 & 10 & 90 & 45 & 58 \\
\hline 9048 & 3 & MAC6 & 1.192 & 37.3 & 59 & 10 & 9 & 43 & 61 \\
\hline 9048 & 3 & p15 & 1.31 & 37.5 & 64 & 8 & . & & \\
\hline 9048 & 3 & p30 & 0.934 & 37.7 & 68 & 8 & . & & \\
\hline 9048 & 3 & p90 & 1.034 & 38 & 60 & 12 & . & & . \\
\hline 9048 & 4 & 0 & 0.383 & 38.1 & 72 & 16 & . & & \\
\hline 9048 & 4 & 15 & 0.682 & 37.3 & 80 & 8 & 101 & 51 & 64 \\
\hline 9048 & 4 & 30 & 0.505 & 35.9 & 73 & 8 & 83 & 46 & 57 \\
\hline 9048 & 4 & MAC1 & 0.621 & 34.2 & 69 & 8 & 105 & 53 & 68 \\
\hline 9048 & 4 & MAC2 & 0.461 & 34.3 & 63 & 8 & 107 & 49 & 78 \\
\hline 9048 & 4 & MAC3 & 0.68 & 34.2 & 51 & 8 & 137 & 69 & 87 \\
\hline 9048 & 4 & MAC4 & 0.578 & 34.2 & 50 & 8 & 156 & 75 & 100 \\
\hline 9048 & 4 & MAC5 & 0.662 & 34.4 & 49 & 8 & 151 & 62 & 83 \\
\hline 9048 & 4 & MAC6 & 0.611 & 34.2 & 49 & 8 & 159 & 63 & 97 \\
\hline 9048 & 4 & p15 & 0.627 & 34.8 & 200 & 20 & . & & \\
\hline 9048 & 4 & p30 & 0.656 & 35.9 & 140 & 20 & & & \\
\hline 9048 & 4 & p90 & 0.734 & 37.2 & 96 & 20 & & & \\
\hline
\end{tabular}




\begin{tabular}{|c|c|c|c|c|c|c|c|c|c|}
\hline Dog & TX & Time & Fent & Temp & HR & $\mathbf{R R}$ & Systolic & Diastolic & Mean \\
\hline 9053 & 1 & 0 & 0 & 38.7 & 96 & 20 & & . & \\
\hline 9053 & 1 & 15 & & 38.2 & 112 & 16 & & 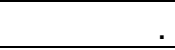 & \\
\hline 9053 & 1 & 30 & & 38 & 110 & 17 & 82 & 54 & 64 \\
\hline 9053 & 1 & MAC1 & & 37.3 & 119 & 13 & 92 & 54 & 70 \\
\hline 9053 & 1 & MAC2 & & 37.3 & 121 & 13 & 92 & 58 & 72 \\
\hline 9053 & 1 & MAC3 & & 37.2 & 120 & 13 & 100 & 66 & 77 \\
\hline 9053 & 1 & p15 & 0 & 37.4 & 100 & 16 & & . & \\
\hline 9053 & 2 & 0 & 0 & 38.4 & 80 & 12 & & & \\
\hline 9053 & 2 & 15 & & 36.4 & 125 & 13 & 99 & 42 & 64 \\
\hline 9053 & 2 & 30 & & 35.6 & 112 & 10 & 71 & 40 & 52 \\
\hline 9053 & 2 & MAC1 & & 34.6 & 87 & 8 & 90 & 53 & 64 \\
\hline 9053 & 2 & MAC2 & & 34.7 & 110 & 18 & 128 & 75 & 94 \\
\hline 9053 & 2 & MAC3 & & 34.7 & 115 & 8 & 126 & 80 & 96 \\
\hline 9053 & 2 & p15 & 0 & 36.5 & 80 & 12 & & . & . \\
\hline 9053 & 3 & 0 & 0.204 & 38.7 & 120 & 12 & & . & \\
\hline 9053 & 3 & 15 & 0.112 & 37 & 106 & 10 & & & \\
\hline 9053 & 3 & 30 & 0.193 & 37.1 & 92 & 10 & 85 & 50 & 61 \\
\hline 9053 & 3 & MAC1 & 0.225 & 37 & 92 & 10 & 84 & 48 & 57 \\
\hline 9053 & 3 & MAC2 & 0.22 & 37.2 & 97 & 10 & 102 & 61 & 72 \\
\hline 9053 & 3 & MAC3 & 0.21 & 37.2 & 93 & 10 & 109 & 61 & 74 \\
\hline 9053 & 3 & MAC4 & 0.182 & 37.2 & 87 & 10 & 113 & 62 & 77 \\
\hline 9053 & 3 & MAC5 & 0.227 & 37.2 & 98 & 10 & 117 & 65 & 79 \\
\hline 9053 & 3 & MAC6 & 0.215 & 37.5 & 86 & 10 & 119 & 61 & 76 \\
\hline 9053 & 3 & p15 & 0.278 & 37.3 & 100 & 12 & & . & . \\
\hline 9053 & 3 & p30 & 0.468 & 37.5 & 92 & 12 & & . & \\
\hline 9053 & 3 & p90 & 0.633 & 38.1 & 124 & 12 & & . & \\
\hline 9053 & 4 & 0 & 0.123 & 38 & 104 & 32 & & . & . \\
\hline 9053 & 4 & 15 & 0 & 35.6 & 124 & 11 & & . & \\
\hline 9053 & 4 & 30 & 0 & 35.6 & 124 & 11 & 80 & 48 & 60 \\
\hline 9053 & 4 & MAC1 & 0 & 34.4 & 102 & 10 & 78 & 49 & 59 \\
\hline 9053 & 4 & MAC2 & 0 & 34.4 & 102 & 10 & 109 & 65 & 78 \\
\hline 9053 & 4 & MAC3 & 0 & 34.7 & 91 & 10 & 128 & 80 & 89 \\
\hline 9053 & 4 & MAC4 & 0 & 35.2 & 96 & 10 & 116 & 64 & 82 \\
\hline 9053 & 4 & p15 & 0.311 & 35.8 & 120 & 24 & & & \\
\hline 9053 & 4 & p30 & 0.741 & 36.6 & 96 & 16 & & . & \\
\hline 9053 & 4 & p90 & 0.693 & 37.4 & 84 & 36 & & . & \\
\hline
\end{tabular}




\begin{tabular}{|c|c|c|c|c|c|c|c|c|c|}
\hline Dog & TX & Time & Fent & Temp & HR & $\mathbf{R R}$ & Systolic & Diastolic & Mean \\
\hline 9054 & 1 & 0 & 0 & 37.6 & 66 & 10 & & & \\
\hline 9054 & 1 & 15 & & 37.3 & 98 & 10 & & & \\
\hline 9054 & 1 & 30 & & 37.1 & 135 & 13 & 99 & 56 & 74 \\
\hline 9054 & 1 & MAC1 & & 37.1 & 149 & 12 & 107 & 65 & 83 \\
\hline 9054 & 1 & MAC2 & & 37.2 & 78 & 9 & 122 & 78 & 91 \\
\hline 9054 & 1 & MAC3 & & 37.5 & 140 & 9 & 113 & 75 & 89 \\
\hline 9054 & 1 & p15 & 0 & 37.3 & 120 & 10 & & . & \\
\hline 9054 & 2 & 0 & 0 & 37.9 & 84 & 16 & & & \\
\hline 9054 & 2 & 15 & & 37.2 & 130 & 10 & & & \\
\hline 9054 & 2 & 30 & & 36.3 & 110 & 10 & 113 & 65 & 80 \\
\hline 9054 & 2 & MAC1 & & 34.3 & 142 & 10 & 101 & 73 & 56 \\
\hline 9054 & 2 & MAC2 & & 34.5 & 126 & 10 & 118 & 89 & 68 \\
\hline 9054 & 2 & MAC3 & & 34.4 & 138 & 10 & 123 & 63 & 85 \\
\hline 9054 & 2 & p15 & 0 & 35.2 & 136 & 20 & & & \\
\hline 9054 & 3 & 0 & 0.848 & 37.7 & 68 & 20 & & & \\
\hline 9054 & 3 & 15 & 0.974 & 37.2 & 68 & 10 & 113 & 56 & 70 \\
\hline 9054 & 3 & 30 & 0.862 & 36.8 & 64 & 10 & 97 & 51 & 66 \\
\hline 9054 & 3 & MAC1 & 0.909 & 37.1 & 62 & 10 & 114 & 56 & 74 \\
\hline 9054 & 3 & MAC2 & 1.008 & 37.2 & 64 & 10 & 120 & 65 & 80 \\
\hline 9054 & 3 & MAC3 & 1.023 & 37.4 & 6 & 10 & 129 & 67 & 85 \\
\hline 9054 & 3 & p15 & 0.951 & 37.7 & 112 & 20 & & . & . \\
\hline 9054 & 3 & p30 & 0.903 & 37.7 & 120 & 20 & & . & \\
\hline 9054 & 3 & p90 & 1.26 & 37.7 & 84 & 20 & & . & \\
\hline 9054 & 4 & 0 & 0.794 & 37.5 & 72 & 18 & & . & \\
\hline 9054 & 4 & 15 & 0.722 & 36.3 & 76 & 14 & & . & \\
\hline 9054 & 4 & 30 & 0.687 & 35.8 & 75 & 14 & 78 & 47 & 56 \\
\hline 9054 & 4 & MAC1 & 0.756 & 34.4 & 129 & 16 & 108 & 66 & 81 \\
\hline 9054 & 4 & MAC2 & 0.791 & 34.2 & 112 & 16 & 135 & 77 & 96 \\
\hline 9054 & 4 & MAC3 & 0.688 & 34.2 & 96 & 18 & 131 & 67 & 86 \\
\hline 9054 & 4 & p15 & 0.782 & 34.2 & 96 & 20 & & . & . \\
\hline 9054 & 4 & p30 & 0.71 & 35.4 & 100 & 16 & & . & \\
\hline 9054 & 4 & p90 & 0.763 & 37.7 & 100 & 16 & & & \\
\hline
\end{tabular}




\begin{tabular}{|c|c|c|c|c|c|c|c|c|c|}
\hline Dog & TX & Time & Fent & Temp & HR & RR & Systolic & Diastolic & Mean \\
\hline 9011 & 1 & 0 & 0 & 38.3 & 80 & 20 & & . & \\
\hline 9011 & 1 & 15 & & 37.6 & 94 & 10 & & & \\
\hline 9011 & 1 & 30 & & 37.4 & 87 & 10 & 114 & 56 & 74 \\
\hline 9011 & 1 & MAC1 & . & 37.4 & 74 & 10 & 121 & 65 & 80 \\
\hline 9011 & 1 & MAC2 & . & 37.4 & 70 & 10 & 130 & 76 & 91 \\
\hline 9011 & 1 & MAC3 & & 37.4 & 56 & 10 & 136 & 70 & 89 \\
\hline 9011 & 1 & MAC4 & & 37.3 & 93 & 10 & 117 & 69 & 83 \\
\hline 9011 & 1 & p15 & 0 & 37.2 & 88 & 18 & & . & \\
\hline 9011 & 2 & 0 & 0 & 37.2 & 60 & 10 & & . & \\
\hline 9011 & 2 & 15 & . & 36.1 & 109 & 10 & . & . & \\
\hline 9011 & 2 & 30 & . & 36.2 & 108 & 10 & 94 & 58 & 70 \\
\hline 9011 & 2 & MAC1 & & 34.7 & 81 & 10 & 103 & 61 & 76 \\
\hline 9011 & 2 & MAC2 & . & 34.4 & 70 & 10 & 114 & 72 & 87 \\
\hline 9011 & 2 & MAC3 & . & 34.4 & 70 & 10 & 128 & 80 & 100 \\
\hline 9011 & 2 & MAC4 & 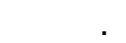 & 34.4 & 98 & 10 & 131 & 80 & 100 \\
\hline 9011 & 2 & p15 & 0 & 35.2 & 100 & 12 & & . & \\
\hline 9011 & 3 & 0 & 0.807 & 37.4 & 60 & 16 & & . & \\
\hline 9011 & 3 & 15 & 1.533 & 35.9 & 87 & 18 & & . & \\
\hline 9011 & 3 & 30 & 1.123 & 35.5 & 76 & 19 & 114 & 60 & 76 \\
\hline 9011 & 3 & MAC1 & 1.149 & 37.4 & 60 & 18 & 115 & 54 & 74 \\
\hline 9011 & 3 & MAC2 & 0.846 & 37.5 & 63 & 18 & 103 & 51 & 66 \\
\hline 9011 & 3 & MAC3 & 0.813 & 37.5 & 61 & 18 & 115 & 90 & 96 \\
\hline 9011 & 3 & MAC4 & 0.808 & 37.5 & 100 & 18 & 106 & 57 & 74 \\
\hline 9011 & 3 & p15 & 0.798 & 37.5 & 100 & 20 & & . & . \\
\hline 9011 & 3 & p30 & 0.783 & 37.5 & 80 & 16 & & & \\
\hline 9011 & 3 & p90 & 0.777 & 37.7 & 60 & 16 & & . & \\
\hline 9011 & 4 & 0 & 0.629 & 37.8 & 72 & 16 & . & . & 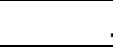 \\
\hline 9011 & 4 & 15 & 0.526 & 35.1 & 67 & 10 & . & . & \\
\hline 9011 & 4 & 30 & 0.708 & 34.6 & 73 & 10 & 87 & 50 & 63 \\
\hline 9011 & 4 & MAC1 & 0.692 & 34.3 & 65 & 10 & 67 & 54 & 61 \\
\hline 9011 & 4 & MAC2 & 0.739 & 34.4 & 59 & 10 & 90 & 54 & 67 \\
\hline 9011 & 4 & MAC3 & 0.812 & 34.3 & 52 & 10 & 97 & 58 & 74 \\
\hline 9011 & 4 & MAC4 & 0.753 & 34.2 & 47 & 10 & 104 & 64 & 82 \\
\hline 9011 & 4 & MAC5 & 0.676 & 34.2 & 40 & 10 & 113 & 61 & 83 \\
\hline 9011 & 4 & MAC6 & 0.747 & 34 & 35 & 10 & 120 & 66 & 87 \\
\hline 9011 & 4 & MAC7 & 0.841 & 34.3 & 35 & 10 & 115 & 70 & 88 \\
\hline 9011 & 4 & p15 & 0.855 & 35 & 128 & 16 & & . & \\
\hline 9011 & 4 & p30 & 0.926 & 36 & 84 & 16 & & & \\
\hline 9011 & 4 & p90 & 1.191 & 37.9 & 64 & 24 & & & \\
\hline
\end{tabular}




\begin{tabular}{|c|c|c|c|c|c|c|c|c|c|}
\hline Dog & TX & Time & Fent & Temp & HR & RR & Systolic & Diastolic & Mean \\
\hline PACC & 1 & 0 & 0 & 39 & 64 & 52 & & & \\
\hline PACC & 1 & 15 & & 38.9 & 95 & 8 & 60 & 30 & 39 \\
\hline PACC & 1 & 30 & . & 38.4 & 66 & 10 & 123 & 53 & 72 \\
\hline PACC & 1 & MAC1 & . & 37.6 & 61 & 10 & 127 & 50 & 69 \\
\hline PACC & 1 & MAC2 & . & 37.5 & 62 & 10 & 121 & 50 & 59 \\
\hline PACC & 1 & MAC3 & . & 37.5 & 66 & 10 & 118 & 50 & 67 \\
\hline PACC & 1 & p15 & 0 & 37.2 & 72 & 16 & & & \\
\hline PACC & 2 & 0 & 0 & 38.7 & 100 & 20 & & & \\
\hline PACC & 2 & 15 & . & 36.8 & 70 & 10 & . & & \\
\hline PACC & 2 & 30 & . & 36 & 68 & 10 & 68 & 47 & 57 \\
\hline PACC & 2 & MAC1 & . & 34 & 75 & 10 & 77 & 39 & 51 \\
\hline PACC & 2 & MAC2 & & 34.3 & 80 & 10 & 107 & 60 & 76 \\
\hline PACC & 2 & MAC3 & . & 34.3 & 73 & 10 & 111 & 58 & 75 \\
\hline PACC & 2 & MAC4 & . & 34.3 & 80 & 10 & 120 & 63 & 84 \\
\hline PACC & 2 & MAC5 & . & 34.3 & 64 & 10 & 125 & 63 & 84 \\
\hline PACC & 2 & MAC6 & . & 34.4 & 72 & 10 & 121 & 60 & 80 \\
\hline PACC & 2 & MAC7 & & 34.4 & 64 & 10 & 120 & 55 & 77 \\
\hline PACC & 2 & p15 & 0 & 35.5 & 140 & 20 & & & \\
\hline PACC & 3 & 0 & 1.607 & 38.3 & 80 & 16 & . & . & \\
\hline PACC & 3 & 15 & 1.127 & 37.8 & 58 & 16 & . & . & \\
\hline PACC & 3 & 30 & 1.499 & 37.8 & 65 & 16 & . & . & \\
\hline PACC & 3 & MAC1 & 1.727 & 37.4 & 34 & 18 & 151 & 45 & 66 \\
\hline PACC & 3 & MAC2 & 1.686 & 37.2 & 37 & 18 & 139 & 48 & 71 \\
\hline PACC & 3 & MAC3 & 1.659 & 37.3 & 35 & 18 & 134 & 44 & 61 \\
\hline PACC & 3 & p15 & 1.72 & 37.5 & 88 & 24 & . & . & \\
\hline PACC & 3 & p30 & 1.519 & 37.9 & 88 & 24 & . & . & \\
\hline PACC & 3 & p90 & 1.389 & 37.8 & 66 & 24 & . & . & \\
\hline PACC & 4 & 0 & 1.003 & 38 & 80 & 10 & . & . & \\
\hline PACC & 4 & 15 & 2.513 & 37 & 50 & 10 & . & 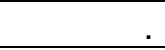 & \\
\hline PACC & 4 & 30 & 2.13 & 36.6 & 59 & 10 & 85 & 33 & 49 \\
\hline PACC & 4 & MAC1 & 1.708 & 34.5 & 44 & 10 & 83 & 31 & 45 \\
\hline PACC & 4 & MAC2 & 1.64 & 34.6 & 52 & 10 & 108 & 48 & 66 \\
\hline PACC & 4 & MAC3 & 1.641 & 34.3 & 49 & 10 & 108 & 46 & 64 \\
\hline PACC & 4 & p15 & 1.405 & 36 & 80 & 14 & . & . & \\
\hline PACC & 4 & p30 & 1.261 & 36 & 100 & 10 & . & . & \\
\hline PACC & 4 & p90 & 1.226 & 37.6 & 80 & 10 & & & \\
\hline
\end{tabular}




\begin{tabular}{|c|c|c|c|c|c|c|c|c|c|}
\hline Dog & TX & Time & Fent & Temp & HR & $\mathbf{R R}$ & Systolic & Diastolic & Mean \\
\hline 9041 & 1 & 0 & 0 & 38.8 & 96 & 16 & . & & \\
\hline 9041 & 1 & 15 & & 37.4 & 100 & 12 & & & \\
\hline 9041 & 1 & 30 & & 37.4 & 89 & 12 & 90 & 54 & 65 \\
\hline 9041 & 1 & MAC1 & & 37.3 & 98 & 12 & 94 & 55 & 64 \\
\hline 9041 & 1 & MAC2 & . & 37.5 & 94 & 12 & 94 & 52 & 64 \\
\hline 9041 & 1 & p15 & 0 & 37.6 & 96 & 12 & . & & \\
\hline 9041 & 2 & 0 & 0 & 38.6 & 80 & 16 & & & \\
\hline 9041 & 2 & 15 & & 37.2 & 113 & 17 & 86 & 51 & 63 \\
\hline 9041 & 2 & 30 & . & 36.7 & 110 & 12 & 111 & 66 & 78 \\
\hline 9041 & 2 & MAC1 & . & 34.2 & 101 & 10 & 89 & 54 & 66 \\
\hline 9041 & 2 & MAC2 & . & 34.1 & 110 & 10 & 118 & 74 & 88 \\
\hline 9041 & 2 & MAC3 & & 34.2 & 120 & 10 & 120 & 70 & 89 \\
\hline 9041 & 2 & MAC4 & & 34.5 & 98 & 17 & 149 & 70 & 103 \\
\hline 9041 & 2 & MAC5 & . & 34.5 & 161 & 17 & 137 & 70 & 90 \\
\hline 9041 & 2 & p15 & 0 & 35.4 & 100 & 20 & . & & \\
\hline 9041 & 3 & 0 & 0.611 & 38.5 & 72 & 16 & . & & \\
\hline 9041 & 3 & 15 & 0.676 & 38 & 118 & 12 & & & \\
\hline 9041 & 3 & 30 & 0.666 & 38 & 107 & 12 & 130 & 63 & 81 \\
\hline 9041 & 3 & MAC1 & 0.823 & 37.5 & 115 & 17 & 116 & 57 & 76 \\
\hline 9041 & 3 & MAC2 & 0.678 & 37.6 & 111 & 16 & 120 & 63 & 82 \\
\hline 9041 & 3 & MAC3 & 0.739 & 37.7 & 116 & 17 & 125 & 71 & 88 \\
\hline 9041 & 3 & MAC4 & 0.746 & 37.7 & 113 & 16 & 121 & 67 & 85 \\
\hline 9041 & 3 & p15 & 1.051 & 37.7 & 128 & 20 & . & & \\
\hline 9041 & 3 & p30 & 0.972 & 37.9 & 136 & 32 & . & & \\
\hline 9041 & 3 & p90 & 0.904 & 38.3 & 116 & 20 & . & & \\
\hline 9041 & 4 & 0 & 0.223 & 38 & 88 & 16 & . & & \\
\hline 9041 & 4 & 15 & 0.409 & 36.9 & 75 & 11 & . & & \\
\hline 9041 & 4 & 30 & 0.461 & 35.9 & 88 & 11 & & & \\
\hline 9041 & 4 & MAC1 & 0.334 & 34.5 & 143 & 10 & 107 & 53 & 75 \\
\hline 9041 & 4 & MAC2 & 0.323 & 34.5 & 110 & 10 & 117 & 58 & 76 \\
\hline 9041 & 4 & MAC3 & 0.342 & 34.5 & 97 & 10 & 120 & 60 & 80 \\
\hline 9041 & 4 & MAC4 & 0.274 & 34.4 & 88 & 10 & 133 & 60 & 80 \\
\hline 9041 & 4 & p15 & 0.239 & 34.4 & 132 & 20 & . & & \\
\hline 9041 & 4 & p30 & 0.264 & 35.2 & 160 & 28 & . & & \\
\hline 9041 & 4 & p90 & 0.216 & 36.9 & 124 & & & & \\
\hline
\end{tabular}




\begin{tabular}{|c|c|c|c|c|}
\hline DOG & TX & MAC & AUC & PAUC \\
\hline $\mathbf{9 0 4 8}$ & 1 & 1.15 & 0 & 0 \\
\hline $\mathbf{9 0 4 8}$ & 2 & 1.055 & 0 & 0 \\
\hline $\mathbf{9 0 4 8}$ & 3 & 0.645 & 279.9 & 87.5 \\
\hline $\mathbf{9 0 4 8}$ & 4 & 0.66 & 150.3 & 37.7 \\
\hline $\mathbf{9 0 5 3}$ & 1 & 1.175 & 0 & 0 \\
\hline $\mathbf{9 0 5 3}$ & 2 & 0.975 & 0 & 0 \\
\hline $\mathbf{9 0 5 3}$ & 3 & 0.73 & 45.86 & 12.24 \\
\hline $\mathbf{9 0 5 3}$ & 4 & 1.02 & 0.9225 & 0 \\
\hline $\mathbf{9 0 5 4}$ & 1 & 1.15 & 0 & 0 \\
\hline $\mathbf{9 0 5 4}$ & 2 & 1.03 & 0 & 0 \\
\hline $\mathbf{9 0 5 4}$ & 3 & 0.69 & 112.1 & 58.34 \\
\hline $\mathbf{9 0 5 4}$ & 4 & 0.86 & 98.75 & 44.99 \\
\hline $\mathbf{9 0 1 1}$ & 1 & 0.94 & 0 & 0 \\
\hline $\mathbf{9 0 1 1}$ & 2 & 0.85 & 0 & 0 \\
\hline $\mathbf{9 0 1 1}$ & 3 & 0.86 & 213.4 & 57.18 \\
\hline $\mathbf{9 0 1 1}$ & 4 & 0.56 & 151.1 & 45.21 \\
\hline PACC & 1 & 1.39 & 0 & 0 \\
\hline PACC & 2 & 0.56 & 0 & 0 \\
\hline PACC & 3 & 0.76 & 237.5 & 102 \\
\hline PACC & 4 & 0.94 & 226.1 & 103.8 \\
\hline $\mathbf{9 0 4 1}$ & 1 & 1.375 & 0 & 0 \\
\hline $\mathbf{9 0 4 1}$ & 2 & 0.84 & 0 & 0 \\
\hline $\mathbf{9 0 4 1}$ & 3 & 0.895 & 118.8 & 43.02 \\
\hline $\mathbf{9 0 4 1}$ & 4 & 0.82 & 58.59 & 19.58 \\
\hline
\end{tabular}

\section{Abbreviations:}

MAC $=$ Minimum alveolar concentration

AUC $=$ Area under the curve

PAUC $=$ Partial area under the curve

TX = treatment (1= C-NORM, 2= F-NORM, 3= C-HYPO, 4= F-HYPO)

Fent $=$ fentanyl concentration

Temp $=$ temperature $\left({ }^{\circ} \mathrm{C}\right)$

$\mathrm{HR}=$ heart rate

$\mathrm{RR}=$ respiratory rate

Systolic, diastolic, mean $=$ blood pressure $(\mathrm{mmHg})$ 
VITA 
Diane Wilson was born in Belfast, Northern Ireland, in 1965. She graduated from Belfast High School in 1982. She attended the North Down and Ards College of Nursing in Dundonald, Northern Ireland, from 1983 to 1987. She obtained her Registered General Nurse qualification in 1987. Diane relocated to the United States of America in 1988 and worked as a critical care nurse in various locations including Los Angeles and Florida.

In 1995 Diane resumed her formal education at Louisiana State University where she was enrolled in the pre-veterinary curriculum. She was accepted to Louisiana State University School of Veterinary Medicine in 1997 and graduated with a Doctor of Veterinary Medicine degree in 2001.

Diane returned to the United Kingdom in 2001 and worked in a busy mixed animal practice in England for one year prior to returning to the U.S.A. to begin a residency in anesthesia and pain management at Louisiana State University. Dr. Wilson will be awarded the degree Master of Science in May 2005 and will complete her residency in July 2005. 